\title{
Nordiques
}

$34 \mid 2017$

La mer Baltique comme zone-frontière : perspectives environnementales, géopolitiques, culturelles

\section{« Notre vie semble aller vers un avenir incertain... » : la frontière orientale, une obsession finlandaise (1917-1922)}

\section{Maurice Carrez}

\section{(2) OpenEdition}

Journals

Édition électronique

URL : https://journals.openedition.org/nordiques/1674

DOI : 10.4000 /nordiques. 1674

ISSN : 2777-8479

Éditeur :

Association Norden, Bibliothèque de Caen la mer

Édition imprimée

Date de publication : 1 novembre 2017

Pagination : 31-60

ISBN : 9791095914006

ISSN : $1761-7677$

\section{Référence électronique}

Maurice Carrez, « « Notre vie semble aller vers un avenir incertain... » : la frontière orientale, une obsession finlandaise (1917-1922) », Nordiques [En ligne], 34 | 2017, mis en ligne le 27 septembre 2021, consulté le 27 novembre 2021. URL : http://journals.openedition.org/nordiques/1674 ; DOI https://doi.org/10.4000/nordiques.1674 


\section{« Notre vie semble aller vers un avenir incertain... ${ }^{1}$ : la frontière orientale, une obsession finlandaise (1917-1922)}

Maurice Carrez ${ }^{*}$

RÉSUMÉ

L'agression soviétique de l'automne 1939 a souvent fait passer la Finlande pour une victime éternelle de la brutalité de son grand voisin. Or, la frontière orientale de ce pays a une histoire beaucoup plus complexe que ne le laisserait penser l'événement précité. En effet, la contestation des limites de l'ancien grand-duché a souvent été, entre 1917 et 1922, le fait des Finlandais eux-mêmes, et pas seulement d'ailleurs des ultranationalistes. Les dirigeants "rouges" de la Délégation du peuple et ceux des gouvernements "bourgeois " qui leur ont succédé ont souvent lorgné vers la Carélie avec des projets d'annexion plus ou moins clairs. La lutte contre le bolchevisme n'a souvent été qu'un prétexte pour annexer ce que beaucoup désignaient comme un "peuple frère " dans la droite lignée du mythe kalévaléen. Les révolutionnaires russes pour leur part ont peut-être eu, ne serait-ce qu'en raison de la fragilité de leur position, des positions plus modérées. C'est ce que cet article va sattacher à montrer en tenant compte à la fois des facteurs conjoncturels et de longue durée.

\section{ABSTRACT}

The Soviet aggression of the autumn of 1939 has often led to think, that Finland has been an eternal victim of the brutality of its great neighbour. In fact, the eastern border of that country has experienced a much more complex history than the above-mentioned event would suggest. Indeed, between 1917 and 1922, the disputes about the boundaries of the old Grand Duchy were often intiated by the Finns themselves, and not only by the ultranationalists among them. The "red" leaders of the People's Delegation and those of the "bourgeois" governments that succeeded them often had their eye on Karelia with clear or not plans for annexation. In most cases, the struggle against Bolshevism was only a pretext for seizing what many people referred to as a "sister nation" in connexion with the myth of the Kalevala. The Russian revolutionaries, on the other hand, took up maybe quite moderate stances, if only in order to safeguard their fragile position. The purpose of this article is to support that assertion, taking both short-term and long-term factors into account.

* Maurice Carrez est professeur d'histoire contemporaine à l'université de Strasbourg, UMR CNRS 7367 Dyname.

1 Gustaf Mannerheim, Muistelmat (Souvenirs), $1^{\text {re }}$ partie, Helsinki, Otava, 1951, p. 441 : extrait d'une lettre ouverte du général et ancien régent à propos de la situation politique quelques semaines après sa défaite aux élections présidentielles, datée de septembre 1919. 
Durant les cinq années qui suivent la déclaration d'indépendance de la Finlande (6 décembre 1917), la question de la frontière orientale du nouvel État est l'objet de nombreuses tensions avec la Russie bolchevique voisine. Le contexte général, il est vrai, s'y prête. La première guerre mondiale ne prend fin qu'un an plus tard ; combinée à la guerre civile finlandaise (fin janvier-mi-mai 1918) ${ }^{2}$, elle amène les troupes allemandes jusqu'à Narva puis sur le territoire national où elles participent dans le Sud aux derniers combats contre les " rouges ", la signature des accords de Brest-Litovsk en mars 1918 ne concernant pas l'ancien grand-duché. La guerre civile en Russie commence dès cette époque et ne s'achève vraiment qu'avec la fin des derniers soulèvements paysans en $1922^{3}$. Or, elle a des répercussions évidentes sur la question frontalière dans la mesure où elle implique l'intervention des Alliés (jusqu'à l'été 1919 de manière directe) et d'importantes difficultés pour le pouvoir bolchevique, obligé de trouver des compromis souvent défavorables. Les rapports entre les gouvernements russe et finlandais s'en ressentent, chacun cherchant à fixer la frontière au mieux de ses intérêts et de son idéologie : épousera-t-elle les limites fixées à l'époque impériale ? S'étendra-t-elle vers l'est comme en rêvent depuis longtemps les nationalistes fennomanes, désireux de prendre sous leur aile les peuples «frères " dans le cadre d'une "Grande Finlande " (Suur-Suomi) ? Sera-t-elle une simple étape pour les bolcheviks dans leur désir d'étendre la révolution prolétarienne?

Si l'on suit à la lettre Robert Service, évoquant la question polonaise en $1920^{4}$, la réponse semble simple : "les documents d'archives les plus récents, écrit-il, confirment l'idée que Lénine avait à nouveau le désir brûlant d'étendre la Révolution d'octobre. Il était prêt à braver les vainqueurs de la guerre mondiale, les Alliés, en suscitant des problèmes au-delà des frontières occidentales de la Russie $"^{5}$. On peut aussi arguer du fait que lorsque Edvard Gylling, futur dirigeant (finlandais) de la Carélie soviétique, propose à Lénine en 1920 la création d'une république

2 Sur cet épisode, Anthony Upton, The Finnish Revolution. 1917-1918, Minneapolis, University of Minnesota Press, 1980 ; id., Punaisen Suomen historia (Histoire de la Finlande rouge), Helsinki, Comité d'histoire de la Garde rouge - Ministère de l'Éducation, 1986, 6 t. ; Jean-Jacques Fol, Accession de la Finlande à l'indépendance. 1917-1919, t. I, Lille, Reproduction des thèses, 1977, p. 379-560 ; Maurice Carrez, La fabrique d'un révolutionnaire. Otto Wilhelm Kuusinen (1881-1918). Réflexions sur l'engagement d'un dirigeant social-démocrate finlandais, t. II, Toulouse, Méridiennes, 2008.

3 Evan Mawdsley, The Russian Civil War, $3^{\text {e }}$ éd., Édimbourg, Birlinn, 2008 ; Jean-Jacques Marie, Histoire de la guerre civile russe. 1917-1922, $2^{\mathrm{e}}$ éd., Paris, Tallandier, 2015 ; id., La guerre des Russes blancs. 1917-1920, Paris, Tallandier, 2017.

4 Robert Service, Lénine [traduction finnoise], Helsinki, WSOY, 2004, début du chap. XXIV.

5 L'auteur se réfere dans ce passage à l'historien russe Anatolii G. Latyšev, Rassekrechennyi Lenin (Le Lénine secret), Moscou, Izd-vo Mart, 1996. Il aurait pu tout aussi bien utiliser, dans la même veine, le général Dimitri Volkogonov, Le vrai Lénine. D’après les archives secrètes soviétiques, trad. de S. Quadruppani et D. Seseman, Paris, Laffont, 1995. À noter que l'usage du mot secret n'est pas neutre. 
autonome, il évoque la possibilité d'étendre à toute la Scandinavie la révolution ${ }^{6}$. Mais beaucoup d'autres sources indiquent que les choses sont sans doute plus compliquées et que la frontière finlandaise constitue un cas d'espèce qu'il n'est sans doute pas pertinent d'interpréter au travers d'une seule grille de lecture, car les plus acharnés à vouloir faire évoluer la longue frontière terrestre entre les deux États autrefois réunis ne sont peut-être pas ceux que l'opinion la plus répandue désigne. Nous essaierons en tout cas de montrer dans ce modeste article qu'il faut essayer d'envisager le problème sans œillères, la limite de notre travail étant le déséquilibre en faveur des sources finlandaises, beaucoup plus utilisées que les sources russes pour des raisons de temps.

Pour ce faire, nous commencerons par montrer que le problème de la frontière orientale de la Finlande a un arrière-plan conflictuel plongeant ses racines assez loin dans l'histoire. Puis nous essaierons de suivre les méandres qu'elle a pris au cours d'une période riche en rebondissements, ce qui nous amènera à adopter un plan chronologique.

\section{UNE FRONTIÈRE EXCITANT DEPUIS LONGTEMPS LES CONVOITISES}

Finlande et Carélie ont été depuis le Moyen Âge, et particulièrement depuis la conquête suédoise du XIII ${ }^{e}$, des territoires disputés entre deux États en pleine croissance : la Moscovie, devenue peu à peu l'Empire tsariste, et le royaume de Suède qui a été jusqu'au XVIII ${ }^{e}$ son concurrent le plus redoutable ${ }^{7}$. Pendant longtemps, les Suédois ont semblé conserver l'avantage au point de constituer un glacis protecteur s'étendant à son apogée des confins de l'océan Arctique à la Livonie, incluant ainsi l'Ingrie ${ }^{8}$ et une bonne partie de la Carélie d'Olonets (Aunus) $)^{9}$. Suite à la défaite de Charles XII à Poltava en juillet 1709, Pierre I ${ }^{\text {er }}$ et ses successeurs sur le trône de Russie reprennent nettement l'avantage ${ }^{10}$. La Finlande est envahie à deux reprises par les troupes du tsar et la frontière orientale finit par être fixée au fleuve Kymi, soit à mi-chemin entre la frontière actuelle et Helsinki. Suite à une énième guerre perdue, le royaume de Suède doit céder le

6 Markku Kangaspuro, Neuvosto-Karjalan taistelu itsehallinnosta. Nationalismi ja suomalaiset punaiset Neuvostoliiton vallankäytössä 1920-1939 (Le combat pour l'autonomie de la Carélie soviétique. Nationalisme et pratique du pouvoir des rouges finlandais en Union soviétique, 1920-1939), Helsinki, SKS, 2000, p. 76 ; Arvo Ylärakkola, Edvard Gylling. Itä-Karjalan suomalainen rakentaja (Edvard Gylling. Bâtisseur finlandais de la Carélie orientale), Helsinki, Otava, 1976, p. 167-168.

7 Pour les changements de frontières au cours des siècles entre les deux États, on peut consulter les cartes du site : https://fi.wikipedia.org/wiki/Suomen_rajamuutokset.

8 L'Ingrie est le territoire qui va de la frontière finlandaise dans l'Isthme de Carélie jusqu'à Narva et qui longe le golfe de Finlande. Les populations finnophones et russophones y étaient mélangées en 1917.

9 On distingue, au sein de la Carélie orientale, c'est-à-dire orthodoxe et appartenant à la Russie, la Carélie d'Olonets (Aunus en finnois), entre les lacs Ladoga et Onega et la Carélie blanche (en finnois Vienan Karjala) qui occupe au nord tout l'espace jusqu'à l'actuel district de Mourmansk.

10 Peter Englund, The Battle that Shook Europe. Poltava and the Birth of the Russian Empire, Londres, Tauris, 2002. 
grand-duché de Finlande à la Russie en 1809 lors de la signature de la paix de Fredrikshamn (Hamina). Alexandre I ${ }^{\text {er }}$, soucieux de ménager ses nouveaux sujets, leur accorde cependant divers privilèges ainsi qu'un statut d'État autonome au sein de l'Empire ; il fixera également beaucoup plus à l'est les frontières jusqu'aux rives du Ladoga et à une quarantaine de kilomètres de Saint-Pétersbourg, ce qui permet au grand-duché de réintégrer l'isthme de Carélie et une partie non négligeable de la Carélie ${ }^{11}$. C'est cette frontière qui devient momentanément celle de la Finlande indépendante en 1917.

Mais les rapports entre États ne suffisent pas à caractériser une frontière. Celleci revêt souvent des aspects idéologiques. Ainsi, dans notre cas précis, la religion a longtemps séparé, comme une sorte de barrière mentale, les orthodoxes tournés vers Novgorod puis Moscou et les chrétiens occidentaux, catholiques puis protestants, dépendants de l'archevêché de Turku ${ }^{12}$. Cette opposition s'atténue quelque peu à partir de la fin du XVIII ${ }^{e}$ siècle, mais sans disparaître. La montée du nationalisme romantique au XIX ${ }^{e}$ joue par contre un rôle de plus en plus important dans la représentation de la frontière. En effet, inspiré des théories de Herder sur la langue comme expression de l'âme d'un peuple, les tenants du romantisme de Turku (apogée entre 1818 et 1823) commencent très tôt à s'intéresser aux langues et aux cultures des populations finno-ougriennes voisines, car ils y voient comme un pont jeté entre peuples "frères "; ils sont les premiers à promouvoir la culture populaire. Zachris Topelius et Elias Lönnrot suivent leur exemple dès les années 1830-1840 en recherchant poèmes et chants anciens, pour l'un auprès de colporteurs venus de Carélie blanche, pour l'autre auprès de bardes y exerçant encore leur $\operatorname{art}^{13}$. Dans leur esprit, c'est en Finlande de l'Est et en Carélie que les "traditions" ancestrales se sont le mieux conservées et que la culture finnoise est sans doute la plus «pure ». De culturelle la question devient d'ailleurs vite politique : en 1844, Paavo Tikkanen présente devant les étudiants et professeurs affiliés à la " Nation carélienne " de l'université d'Helsinki un programme dans lequel il souligne la nécessité de rassembler les "peuples frères " autour des Finnois afin de les arracher aux griffes de la russification ${ }^{14}$. Lidée progresse au point que Topelius en personne considère, dans une série d'articles parus entre 1854

11 Un très beau livre fait le point sur la période russe en Finlande : Matti Klinge, Keisarin Suomi (La Finlande impériale), Helsinki, Schildts, 1997.

12 Pekka Hakamies, "Karjala kulttuurin rajana » (" La Carélie frontière culturelle "), Tieteessä tapahtuu (Événements scientifiques), no 5, 2007, p. 36-39.

13 Une utile synthèse dans Anastassia Trifonova, Suur-Suomen aate ja Itä-Karjala (Lidéal de la Grande Finlande et la Carélie orientale), mémoire de master sous la direction de Janne Saarikivi, Université de Tartu, 2005, p. 11-16, [http://www.ut.ee/Ural/ariste/loputood/Trifonova.BA.pdf].

14 Mauno Jääskeläinen, Itä-Karjalan kysymys. Kansallisen laajennusohjelman synty ja sen toteuttamisyritykset Suomen ulkopolitiikassa vuosina, 1918-1920 (La question de la Carélie orientale. Naissance et tentatives de réalisation du programme d'extension nationale dans la politique extérieure finlandaise, 1918-1920), Helsinki, Helsingin Yliopiston, 1961, p. 20-22. 
et 1855, que la véritable frontière finlandaise devrait aller jusqu'à l'Onega et à la mer Blanche ${ }^{15}$. Au tournant des années 1870-1880, le discours se durcit et une série de publications appellent à lutter contre la russification en marche dans ces contrées : un séminaire est même fondé en ce sens à Sortavala, sur les rives du Ladoga ${ }^{16}$. En 1906, un nouveau pas est franchi avec la fondation de l'Union de la Carélie blanche (Vienan Karjalan Liitto) qui revendique ouvertement l'union entre la Carélie et la Finlande ${ }^{17}$. L'éclatement de la première guerre mondiale radicalise une partie de l'opinion finlandaise et c'est dans ce contexte qu'en 1917, Karl Herman Stenberg, frère de l'activiste indépendantiste Hugo Stenberg, publie un ouvrage très explicite sur les intentions des ultranationalistes, Ostkarelien im Verhältnis zu Russland und zu Finnland, dans lequel il explique les raisons justifiant selon lui l'annexion de la Carélie ${ }^{18}$. C'est au demeurant le 7 avril de cette année-là qu'à l'appel d'organisations nationalistes, deux mille personnes se rassemblent devant l'église de Suomussalmi pour exiger le rattachement de cette dernière à une future Finlande indépendante ${ }^{19}$. Bien que ce courant d'opinion reste minoritaire et instrumentalise en le caricaturant l'idéal romantique, une large majorité de Finlandais se sent proche des autres peuples finno-ougriens et reste persuadée qu'ils ont un destin commun. Même parmi les militants sociaux-démocrates en vue, beaucoup de ceux qui viennent des rangs du nationalisme fennomane ne considèrent pas cette idée comme un simple effet de l'idéologie dominante, car, influencés par leur éducation antérieure, ils se sentent un devoir de solidarité vis-à-vis de populations souvent déshéritées ${ }^{20}$.

Depuis la fin du XIX ${ }^{e}$ siècle, les enjeux économiques ont également leur importance. L'industrie forestière, en plein développement ${ }^{21}$, a besoin de matières premières ; or, les immenses forêts de Carélie constituent un réservoir potentiel qu'elle ne peut négliger. De plus, la demande en papier ayant beaucoup augmenté au cours du conflit mondial et la législation sur la protection des forêts finlandaises ayant beaucoup progressé depuis une dizaine d'années, la peur de voir s'épuiser la ressource grandit. Certains ne verraient pas d'un mauvais oil l'annexion pure et simple de certaines communes frontalières. En outre, la construction de la voie ferrée de Mourmansk à Saint-Pétersbourg à partir de 1915, pour permettre le

15 Anastassia Trifonova, op. cit., p. 20-22.

16 Ibid., p. 29-30.

17 Toivo Nygård, Suur-Suomi vai lähiheimolaisten auttaminen. Aatteellinen heimotyö itsenäisessä Suomessa (La Grande Finlande ou l'aide aux peuples frères. Le travail en faveur de l'idéal grand-finnois dans la Finlande indépendante), Keuruu, Otava, 1978, p. 43-45.

18 Mauno Jääskeläinen, Itä-Karjalan..., op. cit., p. 59-60.

19 Anastassia Trifonova, Suur-Suomen aate..., op. cit., p. 38-39.

20 Maurice Carrez, La fabrique ..., op. cit., t. I, chap. IV et V.

21 Markku Kuisma, Metsäteollisuuden maa. Suomi, metsät ja kansainvälinen järjestelmä, 1600-1920 (La Finlande, pays de l'industrie forestière. La Finlande, les forêts et le système international, 1600-1920), Helsinki, SHS, 1993. 
ravitaillement par les Alliés de l'armée russe, renforce l'attractivité de la zone qui se trouve de surcroît au centre d'enjeux stratégiques et militaires.

Cet arrière-plan dessine une trame dont les différents acteurs de notre période doivent tenir compte, quelle que soit leur nationalité ou leur idéologie ; il détermine une bonne partie de leurs actions, même s'il s'y mêle, à différentes échelles, des considérations plus conjoncturelles.

\section{DÉCEMBRE 1917 - AVRIL 1918 : VERS UN ACCORD POSSIBLE ?}

Cette période est caractérisée par quatre éléments majeurs : la déclaration d'indépendance de la Finlande, reconnue par la Russie et les principales puissances début janvier 1918 ; la guerre civile finlandaise (28 janvier-16 mai 1918), marquée par des combats acharnés et une violence sans précédent ${ }^{22}$; l'instabilité de la situation en Russie où les bolcheviks, alliés aux socialistes révolutionnaires de gauche, sont isolés et déjà confrontés à des tentatives de soulèvement avant même la dissolution de l'Assemblée constituante (janvier 1918) et la signature du traité de Brest-Litovsk (mars 1918) ${ }^{23}$; enfin, la poussée vers l'est et le nord des armées allemandes qui ont pris Riga en septembre 1917, s'emparent du nord de la Lettonie et de l'Estonie en février 1918 et débarquent en avril à Hanko, appelées à la rescousse par le gouvernement blanc de Vaasa ${ }^{24}$.

Quand les partis finlandais de droite et du centre, tout juste vainqueurs des élections législatives, décident, suite à l'arrivée des bolcheviks au pouvoir à Petrograd, de se séparer coûte que coûte de l'ancienne métropole, ils ne sont pas encore en mesure d'exiger ouvertement la modification des frontières du grand-duché : leur principale préoccupation est d'obtenir une reconnaissance internationale.

22 Heikki Ylikangas, Tie Tampereelle, 1918. Dokumentoitu kuvaus Tampereen antautumiseen johtaneista sotatapahtumista Suomen sisällissodassa (La route vers Tampere, 1918. Description documentée des événements militaires ayant suivi la reddition de Tampere durant la guerre civile finlandaise), Helsinki, WSOY, 1993 ; Markku Tikka, Antti Arponen, Koston kevät. Lappeenrannan teloitukset 1918 (Le printemps de la vengeance. Les exécutions de Lappeenranta en 1918), Helsinki, WSOY, 1918 ; Jaakko Paavolainen, Poliittiset väkivaltaisuudet Suomessa 1918 (Les violences politiques en Finlande en 1918), Helsinki, Tammi, 1966, t. I, Punainen terrori (La terreur rouge), t. II, Valkoinen terrori (La terreur blanche) ; en français, Maurice Carrez, "Les violences de la guerre civile finlandaise de 1918 : enjeux d'histoire, enjeux de mémoire " ("Las violencias de la guerra civil finlandesa : los retos historicos y memoriales " / "The Finnish civil war violences : historical and memorial challenges "), Hispania Nova. Primera revista de historia contemporanea on-line en castellano. Secunda Época, no 13 , dossier spécial sur les guerres civiles en Finlande, Grèce et Argentine, mars 2015, p. 247-265.

23 Evan Mawdsley, The Russian..., op. cit., chap. II et III, p. 21-61.

24 Sur les circonstances précises de cet appel matérialisé par la visite à Berlin du principal dirigeant blanc, Per Svinhufvud, voir Einar W. Juva, P. E. Svinhufvud, t. II (1917-1944), Helsinki-Porvoo, WSOY, 1961, p. 144-162. On trouve de nombreux documents concernant les tractations dans le fonds "Auswärtiges Amt » des Archives nationales finlandaises (Kansallisarkisto) : Abteilung I A « Russland 63 » et "Finnland 1: Allgemeine Angelegenheiten ", cartons 131-132 (nous utiliserons désormais le sigle KA A.A. pour désigner ce fonds). 
Toutefois, durant quatre longues semaines, celle-ci n'avance guère. En effet, le nouveau Sénat (nom de l'exécutif) ne veut pas négocier avec le Commissariat du peuple alors que les puissances belligérantes font dépendre leur décision de l'acceptation formelle du nouveau gouvernement russe qu'elles n'ont pas intérêt sur le moment à mécontenter. Pourtant les bolcheviks répètent depuis longtemps qu'ils sont disposés à accorder cette indépendance si les Finlandais la souhaitent. De plus, les sociaux-démocrates finlandais ne sont pas un obstacle puisqu'ils ont voté cette décision comme un seul homme le 6 décembre 1917, malgré les réserves qu'ils ont formulées à l'égard de la manière dangereuse dont procèdent leurs adversaires politiques. Finalement, malgré sa répugnance, le président du Sénat, P. E. Svinhufvud, doit se rendre à Canossa, en l'occurrence au palais de Smolny, début janvier 1918 afin d'y décrocher le sésame tant attendu ${ }^{25}$. Il n'est pas encore question alors de discuter ouvertement de nouvelles frontières, celles existantes semblant pour le moment faire l'affaire puisque les deux gouvernements sont aux prises avec une situation intérieure délicate. Le 14 janvier 1918, Per Svinhufvud fait même savoir au Parlement qu'un comité mixte (où il y aura des représentants des différents groupes) va être créé avec les Russes pour discuter des questions encore en suspens ${ }^{26}$.

Il existe néanmoins dans chaque pays d'importantes forces hostiles au compromis comme au statu quo. Côté russe, les généraux qui se préparent à prendre leur revanche sur les bolcheviks et leurs alliés ${ }^{27}$, gangrenés de panslavisme, se refusent pour le moment à entériner l'indépendance de la Finlande, tout comme les cadets de Milioukov ou les anciens amis de Kerenski, toujours actifs. Côté finlandais, les activistes, c'est-à-dire la frange la plus déterminée des nationalistes et la plus favorable à l'alliance avec le Reich, la conquête de la Carélie n'est pas une option, mais une obligation ; ils pensent que la fragilité du régime bolchevique peut favoriser leurs plans ${ }^{28}$. Or, ils rencontrent au sein de la droite traditionnelle des échos de plus en plus larges ${ }^{29}$. Après la prise de pouvoir par le Parti socialdémocrate appuyé sur les Gardes rouges de la capitale et des grandes villes du Sud,

25 Sur ces événements, en français, Louis Clerc, La Finlande et l'Europe du Nord dans la diplomatie française. Relations bilatérales et intérêt national dans les considérations finlandaises et nordiques des diplomates et militaires français, Bruxelles, Peter Lang, 2011, p. 40-55 ; Maurice Carrez, La fabrique..., op. cit., t. II, p. 666-710.

26 Ulkoasiain ministeriön arkisto (Archives du ministère des Affaires étrangères) - UMA - Fb 12 "Suomen ulkopolitiikka ja poliittiset suhteet muihin maihin 1918-1950 " (La politique extérieure finlandaise et les rapports politiques aux autres pays »), $12 \mathrm{~L}$ "Neuvostoliitto 1918-1919 " (Union soviétique, 1918-1919») : 14 janvier 1918, "Suomen eduskunnalle » (Au Parlement finlandais).

27 Jean-Jacques Marie, Histoire de la guerre civile..., op. cit., p. 32-36.

28 Sur ce point, Martti Ahti, Ryssän vihassa. Elmo Kaila, 1888-1935. Aktivistin asevoimien harmaan eminenssin ja Akateemisen Karjala Seuran puheenjohtajan elämäkerta (Empli de la haine du Russkof. Elmo Kaila, 1888-1935. Biographie d'un activiste éminence grise des forces armées et président de la Société académique carélienne), Helsinki, WSOY, 1999, est l'ouvrage à consulter.

29 Jean-Jacques Fol, Accession..., op. cit., p. 383-391. 
le gouvernement "blanc" ou "bourgeois ", réfugié à Vaasa, est déjà en pourparlers avec Berlin dans l'espoir de réaliser un tel plan, car les chefs de l'ancien parti de la conciliation avec Saint-Pétersbourg, le Parti finnois, sont en train de basculer vers une ligne dure, y compris Juho Kusti Paasikivi ${ }^{30}$ dont la réputation de modération n'est alors qu'un souvenir ; un autre de ses chefs, Ernst Nevanlinna, est même prêt à céder les îles Åland aux Allemands contre une aide militaire ${ }^{31}$ destinée vraisemblablement à vaincre les Gardes rouges et à chasser les troupes russes au-delà de la frontière ; leur organe de presse, Uusi Suomi (Finlande nouvelle), publie le 25 janvier 1918 un article dans lequel il justifie le recours à l'Allemagne et laisse entendre à mots couverts que l'appel aux Allemands est déjà motivé par le désir de conquérir la Carélie et d'installer en Finlande un régime monarchique ${ }^{32}$; un peu plus tard, un journal de Stockholm, Aftonbladet, rapporte des confidences que Svinhufvud aurait faites à ce sujet dans une interview à un journal allemand lors de sa visite à Berlin ${ }^{33}$.

Le soulèvement rouge du 28 janvier 1918 ouvre néanmoins d'autres horizons. Dès le lendemain de la prise de pouvoir, deux membres éminents de la Délégation du peuple (Kansan valtuuskunta), Yrjö Sirola et Kullervo Manner, se rendent auprès du comité de zone bolchevique à Helsinki pour s'enquérir des conditions d'une entente sur le terrain ${ }^{34}$. Le 31 janvier, Sirola présente à ses collègues un projet d'accord avec le Commissariat du peuple prévoyant entre autres l'indépendance et la neutralité finlandaise, le renvoi négocié des dernières troupes russes et l'ouverture de discussions sur la frontière commune. Il préconise aussi la mise en place d'une commission de cinq membres pour réfléchir à l'établissement d'un texte destiné à des pourparlers d'État à État avec les Russes ${ }^{35}$. Le 8 février, un premier brouillon, objet de plusieurs corrections, est établi, qui prévoit, élément significatif, l'ouverture d'une discussion sur le rattachement éventuel de la Carélie orientale à la Finlande ${ }^{36}$. Ce fait montre qu'une majorité de la Kansanvaltuuskunta (Délégation du peuple) ne partage pas vraiment les propos tenus la veille à un journaliste du Manchester Guardian par Oskari Tokoi selon lesquels une union

30 Archives nationales (Kansallisarkisto), fonds Paasikivi, K VI : 21.

31 Hannu Salokorpi, Pietarin tie. Suomalainen puolue ja suomettarelainen politiikka helmikunn Manifestistä Tarton rauhaan 1920 (Le chemin de Saint-Pétersbourg. Le Parti vieux-finnois et sa politique du Manifeste de février 1899 jusqu'à la paix de Tartu en 1920), Helsinki, SHS, 1988, p. 193.

32 Seppo et Marjaliisa Hentilä, Saksalainen Suomi. 1918 (La Finlande allemande. 1918), Helsinki, Siltala, 2016, p. 302.

33 Aftonbladet, 13 mars 1918 ; voir également Einar W. Juva, P. E. Svinhufvud, op. cit., p. 156-157; Markku Kangaspuro, Neuvosto-Karjalan taistelu..., op. cit., p. 67.

34 Osmo Rinta-Tassi, Kansanvaltuuskunta punaisen. Suomen hallituksena (La Délégation du peuple. Gouvernement de la Finlande rouge), Helsinki, Comité d'histoire de la Garde rouge - Ministère de l'Éducation, 1986, p. 418.

35 Archives nationales (KA), fonds de la Délégation du peuple, minutes des séances, 31 janvier 1918.

36 Osmo Rinta-Tassi, Kansanvaltuuskunta..., op. cit., p. 421. 
fédérative avec une Russie socialiste n'est pas à exclure ${ }^{37}$. Ceux-ci sont d'ailleurs très vite rendus caducs par la rupture des négociations de Brest-Litovsk entraînant la ruée des troupes du Reich sur les provinces baltes et obligeant les bolcheviks à signer le 3 mars un traité très défavorable où ils renoncent à toute prétention sur la Finlande. Entre temps néanmoins, les tractations entre la Commissariat du peuple et la Kansanvaltuuskunta avancent à grands pas. Cette dernière envoie cinq de ses membres dès le 15 février à Petrograd où elle rencontre Lénine et Trotski ; il y est question des demandes finlandaises, plutôt bien accueillies par le premier nommé, et même de l'indépendance de l'Estonie vivement souhaitée par les Finlandais ${ }^{38}$. Le 19 février, c'est au tour d'une délégation bolchevique, emmenée par Cheinman, de participer aux travaux de la Kansanvaltuuskunta ${ }^{39}$. Lors d'une synthèse d'étape le 25 février, les dirigeants bolcheviques de Petrograd estiment que les concessions faites vont trop loin ; cela contraint la partie finlandaise à faire appel à l'arbitrage de Lénine qui leur est plutôt favorable ${ }^{40}$. Finalement, le traité fixant la nouvelle frontière et les modalités du retrait des troupes russes est signé le $1^{\text {er }}$ mars 1918. En échange de la forteresse d'Ino, sur l'Isthme de Carélie, les Finlandais reçoivent le territoire de Petsamo leur donnant accès à l'océan Arctique et à ses ressources en nickel. Le sort de la Carélie orientale n'est pas directement abordé dans le traité, mais les négociateurs ont convenu ensemble de continuer à y réfléchir ${ }^{41}$. Il faut dire que la majorité de la Délégation du peuple est très favorable à l'option d'une annexion, comme le prouvent les propos d'Otto Wilhelm Kuusinen rapportés par l'un des négociateurs finlandais, Sulo Wuolijoki ${ }^{42}$. Côté russe, les réticences sont réelles et il y a un vif débat comme le rappellera un an plus tard Lénine au VIII ${ }^{e}$ congrès du PC(b)R : « ... avec le gouvernement rouge (finlandais) qui n'a pas duré bien longtemps, nous avons conclu un traité, nous lui avons accordé certaines concessions territoriales au sujet desquelles j'ai entendu pas mal d'objections purement chauvines... Ce sont des objections qui m'ont fait dire : "Grattez tel communiste, et vous découvrirez le chauvin grand-russe" $»^{43}$.

Toujours est-il que l'hostilité au traité du $1^{\text {er }}$ mars est très forte du côté des conservateurs des deux pays. Les adversaires des bolcheviks en Russie n’ont pas de

37 Ibid., p. 423.

38 Archives nationales, fonds de la Délégation du peuple, minutes des séances, 13 et 18 février 1918.

39 Ibid., 19 février 1918.

40 Osmo Rinta-Tassi, Kansanvaltuuskunta..., op. cit., p. 422-423.

41 Archives nationales, fonds de la Procurature auprès des tribunaux chargés des crimes contre l'État lors de l'année 1918 (Valtiorikosoikeuksien syyttäjistön arkisto vuonna 1918, VROSyA), Ca 7, lettre d'Edvard Gylling au tribunal de Turku datée du 2 juin 1918, reproduite dans John H. Hodgson, Edvard Gylling ja Otto W. Kuusinen asiakirjojen valossa, 1918-1920 (Edvard Gylling et Otto W. Kuusinen à la lumière des documents, 1918-1920), Helsinki, Tammi, p. 56-57.

42 Maurice Carrez, La fabrique..., op. cit., t. II, p. 761.

43 Lénine, Euvres complètes, t. XXIX, "Rapport sur le programme du parti », Paris - Moscou, Éditions sociales - Éditions du Progrès, 1967, p. 194. 
mots assez durs pour condamner les concessions faites lors de l'accord. Les blancs finlandais estiment pour leur part que les rouges ne songent qu'à brader les intérêts du pays, en s'appuyant sur le fait que le tsar Alexandre II avait jadis promis d'accorder Petsamo sans contrepartie, promesse au demeurant jamais tenue ; ils enragent surtout de voir que les défenses de Petrograd sont nettement renforcées par la présence de troupes russes à Ino ; en effet, la possession de ce fort, situé en face de Krasnaïa Gorka, sur la commune finlandaise d'Uusikirko, rend quasi impossible une attaque massive sur Cronstadt. Le chef de l'armée blanche, le baron Gustaf Mannerheim, n'est pas en reste ; il lance le 23 février 1918 devant les troupes du corps d'armée de Carélie qu'il est venu visiter et encourager dans leur combat contre les Gardes rouges, le fameux "Ordre du jour du fourreau » (Miekantuppipäiväkäsky) dans lequel il affirme, martial, qu'il ne remettra pas son épée au fourreau avant d'avoir chassé les "bandits bolcheviques " de Carélie orientale. Il rencontre, il est vrai, le scepticisme de certains de ses officiers, alors en difficulté sur le front ; il cherche aussi à minimiser un peu plus tard la portée de ses déclarations au représentant allemand en Finlande après la prise, début mars 1918, de Tampere. Mais «il est déjà passé des paroles aux actes " puisqu'il donne l'ordre le 15 mars 1918 à deux unités militaires de franchir la frontière en prenant toutefois la précaution de les inciter à la modération en cas de rencontre avec les troupes britanniques occupant depuis quelque temps Mourmansk et une partie de la voie ferrée menant à Petrograd ${ }^{44}$. Il rejoint ainsi le désir des activistes de passer à l'action coûte que coûte. Le 21 mars 1918, une troupe de volontaires franchit donc la frontière à Suomussalmi en direction de Petrozavodsk (Petroskoi). Neuf jours plus tard, un deuxième contingent, à la tête duquel se trouve le capitaine de Jäger ${ }^{45}$ Toivo Kuisma, se rue en direction d'Olonets (Aunus) ${ }^{46}$. Le but de cette double expédition est de voir les Caréliens se soulever contre les bolcheviks et leurs alliés finlandais accusés de spolier et de terroriser la population civile. En fait, les autochtones regardent ces « libérateurs » avec méfiance et le Royaume-Uni qui redoute une intervention allemande proteste violemment contre une expédition qui peut mettre en danger la voie ferrée de Mourmansk ${ }^{47}$. Pour se justifier, le gouvernement blanc de Vaasa répond que son « intention était seulement d'écraser la révolte rouge en Finlande, de revenir à l'organisation légale et de purger le pays de la soldatesque russe ». Le Foreign Office ne se laisse pas

44 Seppo et Marjaliisa Hentilä, Saksalainen..., op. cit., p. 302.

45 Le régiment de Jäger (en finnois, Jääkärit) était composé d'exilés nationalistes finlandais ayant rejoint l'Allemagne via la Suède à partir de février 1915. Il a combattu sur le front de Riga. Seule une partie des Jäger a rejoint les blancs en 1918, une bonne partie se refusant à venir combattre les rouges, voire rejoignant ces derniers.

46 Jussi Niinistö, Heimosotien historia. 1918-1922 (Les guerres pour "la libération des peuples frères». 1918-1922), $2^{\mathrm{e}}$ éd., Helsinki, SKS, 2016, p. 22-52, fournit maints détails sur ces raids.

47 Tuomo Polvinen, Venäjän vallankumous ja Suomi (La révolution russe et la Finlande), t. I, Helmikuu 1917-toukokuu 1918 (Février 1917-mai 1918), Helsinki-Porvoo, WSOY, 1967, p. 291-298. 
amadouer et menace de rompre les tractations sur une éventuelle aide alimentaire à un pays affamé ; il s’attire une réponse en forme de défi : « le gouvernement finlandais considère [...] comme nécessaire de déclarer qu'on n’a pas le droit de gêner les efforts la population carélienne pour réaliser sa volonté de s'unir dans l'avenir à ses frères dans le cadre d'une Finlande libre et indépendante ${ }^{48}$. Mis sous pression diplomatique et sans vrai soutien des autochtones, les volontaires finlandais doivent toutefois rebrousser chemin dès le 10 avril, suite à une contreattaque des bolcheviks ${ }^{49}$. Contraint au réalisme par les clauses drastiques du traité de Brest-Litovsk, Lénine envoie pour sa part le $1^{\text {er }}$ avril un télégramme courroucé aux responsables de la Commune de Petrograd les enjoignant de faire revenir surle-champ les Gardes rouges russes partis aider leurs homologues finlandais en grande difficulté face aux offensives des blancs ${ }^{50}$. À ce stade, et bien que l'autre camp ait eu aussi ses extrémistes, on voit que l'agressivité sur la frontière russo-finlandaise est surtout à mettre au compte des dirigeants blancs finlandais. D'autres forces d'ailleurs viennent à leur secours. C'est ainsi que le 7 avril 1918, alors que la division de Rüdiger von der Goltz fond sur les arrières des rouges en retraite afin de renforcer la position stratégique du Reich dans la zone baltique, une lettre envoyée par les milieux nationalistes d'Ingrie parvient au service d'espionnage de l'armée blanche ; elle demande l'extension du front pour favoriser un soulèvement des Ingres contre les bolcheviks. Il leur est répondu de faire une demande d'aide officielle, ce qui a valeur d'encouragement ${ }^{51}$. Le 24 avril, le $5^{\mathrm{e}}$ régiment de Jäger finlandais se lance quant à lui à l'assaut de la forteresse d'Ino occupée, conformément à l'accord du $1^{\text {er }}$ mars, par des troupes russes ${ }^{52}$. Celles-ci ne sont absolument pas décidées à abandonner la partie et résistent, ce qui déclenche un incident diplomatique sérieux et contraint dès le 8 mai Svinhufvud à écrire au chancelier von Hertling pour demander l'aide des Allemands dans cette affaire ${ }^{53}$.

\section{MAI 1918 - OCTOBRE 1918 : L'OPTION ALLEMANDE ET SES RISQUES}

La situation doit cependant tenir compte, dès la mi-mai et la victoire définitive des blancs finlandais, de quatre nouveaux facteurs : la décision allemande de laisser sur le sol finlandais une bonne partie de la division von der Goltz (à la demande du gouvernement Svinhufvud), la fin de la coalition entre bolcheviks et $S R$ de gauche, le brusque regain de la guerre civile en Russie et en Ukraine

48 Cité par Einar W. Juva, P. E. Svinhufvud, op. cit., p. 179-180.

49 Markku Kangaspuro, Neuvosto-Karjalan taistelu..., op. cit., p. 67-68.

50 Lénine, Euvres complètes, op. cit., t. XLIV, p. 49.

51 Pekka Nevalainen, Rautaa Inkerin rajalla. Inkerin kansalliset kamppailut ja Suomi, 1918-1920 (Du fer à la frontière d'Ingrie. Les combats nationaux de l'Ingrie et la Finlande, 1918-1920), Helsinki, SHS, 1996 , p. 40.

52 Markku Kangaspuro, Neuvosto-Karjalan taistelu..., op. cit., p. 67-68.

53 KA, A.A., Bd 5, lettre du 8 mai 1918 de Svinhufvud à Hertling. 
("Vendée cosaque ${ }^{54}$ de mai à novembre 1918 ; soulèvements antibolcheviques en Sibérie et dans l'Oural ${ }^{55}$, formation de "l'Armée des volontaires" dans le $\mathrm{Sud}^{56}$ ) et l'intervention de plus en plus voyante des Alliés dans la politique russe et finlandaise.

En ce qui concerne Ino, l'action diplomatique semble prendre le dessus : les soldats russes quittent la forteresse le 14 mai. Mais comme l'affaire risquait d'avoir des prolongements imprévus, elle met les gouvernements belligérants en émoi. Le Foreign Office fait savoir au représentant finlandais à Londres, Rudolf Holsti, qu'il ne faudrait pas donner trop de marge aux Allemands et qu'il conviendrait de signer dès que possible une paix avec les bolcheviks ${ }^{57}$. Le représentant allemand à Helsinki, von Brück, est lui aussi prêt à écouter les arguments des Russes dont il reconnaît qu'ils sont plutôt enclins à calmer le jeu ${ }^{58}$. Suivant les consignes de ses supérieurs à Berlin, il demande au gouvernement blanc finlandais réinstallé à Helsinki de lui transmettre les conditions auxquelles il serait prêt à traiter avec les soviétiques. Il a alors tout loisir de constater que les nouvelles autorités ne souhaitent pas vraiment l'apaisement. L'arrivée des troupes allemandes sur le sol finlandais au tout début du printemps donne en effet aux activistes et aux conservateurs une nouvelle assurance. La conquête de territoires plus à l'est parait à leur portée ; certes les accords de Brest-Litovsk empêchent en principe la division de von der Goltz d'intervenir contre les Russes, mais elle est largement de taille à tenir en respect des rouges vaincus, en fuite au-delà de la frontière ou enfermés par dizaines de milliers dans des camps de concentration. Fin mai, Heikki Renvall envoie à von Brück la réponse (en allemand) concernant les préalables posés par les Finlandais à une paix avec la Russie. C'est un véritable ultimatum en sept points qui ne laisse en fait aucune marge possible à une quelconque négociation. La direction finlandaise exige l'abandon de toute aide aux rouges finlandais sur le territoire russe ainsi que l'annulation des accords du $1^{\text {er }}$ mars avec la Délégation du peuple (point 2), l'annexion, sans qu'aucun référendum ne soit mentionné, de " la Carélie orientale jusqu'au lac Onega et à la mer Blanche, la presqu'île de Kola incluse » (point 3), le remboursement de toutes les personnes privées ayant subi des réquisitions ou des dommages de la part des rouges finlandais lors de la guerre civile (point 4), en partant du principe que ces derniers ne sont que le bras armé de l'armée russe, et, cerise sur la gâteau, la prise en charge par Moscou des dommages que les Finlandais s'étaient engagés par traité à payer aux Allemands pour

54 Evan Mawdsley, The Russian..., op. cit., chap. VII, p. 117-135.

55 Ibid., chap. VIII, p. 136-153 ; Jean-Jacques Marie, La guerre des..., op. cit., chap. V, p. 119-158.

56 Ibid., chap. II, p. 41-62.

57 Jukka-Pekka Pietiäinen, Rudolf Holsti. Lehtimies, tiedemies, poliitikko 1881-1919 (Rudolf Holsti. Journaliste, homme de science et homme politique, 1881-1919), Helsinki, Weilin+Göös, 1986, p. 290-291.

58 UMA, Fb 12, $12 \mathrm{~L}$ : «Venäjä 1918 » (La Russie 1918) : télégramme envoyé vers Berlin le 17 mai 1918. 
la confiscation de leurs bateaux de commerce et de leurs cargaisons ${ }^{59}$. Finalement, sous la pression des Allemands, ils finissent par signer un accord minimaliste à la fin juillet 1918, contresigné par Tchitcherine et Tavaststjerna ${ }^{60}$. Mais le cœur n'y est pas et la méfiance domine.

Les troupes finlandaises n’hésitent pas non plus à pénétrer dans la bande de Petsamo début mai 1918 alors que l'affaire d'Ino n'est pas encore réglée. Mais les soldats britanniques, conscients que la Finlande est désormais alliée dans les faits à l'Allemagne, repoussent l'assaut. La tension est d'autant plus vive que le 26 juin 1918, le chargé d'affaires finlandais à Stockholm fait passer à l'ambassadeur britannique sur place une note de son gouvernement estimant que les armées de Londres occupent illégalement un territoire qui revient « de droit » à la Finlande. Le ton péremptoire de ce document n'est pas fait pour rassurer les diplomates et le gouvernement londoniens ${ }^{61}$.

Aux vues finlandaises sur Petsamo s’ajoutent celles portant sur la Carélie. Dès le 17 mai 1918, Rudolf Holsti reçoit de son ministre de tutelle l'ordre de rencontrer Lord Hardinge, sous-secrétaire permanent auprès du Foreign Office, afin de lui expliquer les avantages qu'aurait une annexion de cette zone par Helsinki. Les Britanniques y mettent deux conditions qu'ils savent impossibles : le départ des Allemands et l'accord des populations ${ }^{62}$. C'est une manière de gagner du temps et de protéger ainsi la voie de Mourmansk qu'ils souhaitent conserver sous leur coupe comme moyen de pression sur les bolcheviks, quitte à s'allier avec la Légion de Mourmansk ${ }^{63}$, un contingent de six cents rouges finlandais mené, au grand dam des autres dirigeants sociaux-démocrates réfugiés en Russie, par Oskari Tokoi ! Lord Hardinge, qui rencontre de nouveau Holsti le 19 juillet 1918, lui rappelle par ailleurs que la Russie reste en principe l'alliée de l'Angleterre, bien que celle-ci ne reconnaisse pas le Commissariat du peuple. Pour cette raison, le Royaume-Uni ne peut pas demander que des territoires soient détachés d'un pays avec lequel elle entretient des relations ; il souhaite surtout que la Finlande respecte la neutralité qu'elle avait initialement proclamée ${ }^{64}$.

59 KA, A.A., Bd 7, L 082237, télégramme de Renvall à von Brück, 27 mai 1918.

$60 \mathrm{UMA}, \mathrm{Fb} 12,12 \mathrm{~L}$ : traduction finnoise de l'accord russo-finlandais du 23 juillet 1918. Celui-ci porte essentiellement sur des échanges de prisonniers, les modalités de passage de la frontière et la mise en place d'une représentation dans chacun des deux pays par le biais du consulat allemand à Petrograd et du consulat norvégien à Helsinki. Un paragraphe est consacré aussi à l'interdiction de la propagande hostile.

61 Jukka-Pekka Pietiäinen, Rudolf Holsti..., op. cit., p. 305.

62 Ibid., p. 295-296.

63 Sur cet épisode, voir Jukka Taneli Nevakivi, Muurmannin legioona. Suomalaiset ja Liittoutuneiden interventio Pohjois-Venäjälle 1918-1919 (La Légion de Mourmansk. Des Finlandais et l'intervention des Alliés en Russie septentrionale, 1918-1919), Helsinki, Tammi, 1970.

64 Jukka-Pekka Pietiäinen, Rudolf Holsti..., op. cit., p. 307-308. 
La direction allemande hésite sur la réponse à donner aux revendications finlandaises. Le secrétaire d'État aux Affaires étrangères, von Kühlmann, dans un long télégramme du 25 mai 1918 à l'état-major et à la direction de la flotte de guerre, n'écarte pas totalement l'hypothèse d'une intervention directe en Carélie, mais, citant son représentant à Moscou, le comte von Mirbach, il souligne que cela risque de fâcher les Russes. Il émet aussi l'hypothèse d'une entente provisoire avec ces derniers pour chasser les Anglais de Mourmansk ${ }^{65}$. En principe, les accords de Brest-Litovsk obligent Berlin à une certaine réserve. Mais en même temps, ils sont conscients que la présence d'un allié s'étendant plus à l'est ne serait pas non plus défavorable, d'autant que la guerre civile rend très fragile la position du Commissariat du peuple. Dans son journal, Juho Kusti Paasikivi note à la date du 17 juillet 1918 qu'il a reçu une proposition allemande d'union militaire dans laquelle est explicitement mentionnée une aide pour la conquête de la Carélie ${ }^{66}$. Cette option est discutée le 30 juillet lors d'une réunion des membres vieuxfinnois du Sénat qui la trouvent favorable aux intérêts politiques des monarchistes $^{67}$. Il faut dire qu'ils ont un allié de poids en la personne de Ludendorff qui fait télégraphier par le général von Berckheim à l'administration des Affaires étrangères qu'il serait favorable à une attaque éclair des Finlandais en Carélie à condition que les Russes ne sachent rien des intentions allemandes ${ }^{68}$. Mais la prudence de von Kühlmann finit par imposer une ligne de compromis avec les Russes : le 8 août 1918, Rüdiger von der Goltz reçoit de l'OHL (le haut commandement allemand) l'ordre de se préparer à marcher sur la voie ferrée de Mourmansk $^{69}$; mais il est mentionné que cette intervention se fera avec l'accord du gouvernement bolchevique qui souhaite affaiblir les Britanniques.

Cinq jours plus tard, Tchitcherine, le commissaire aux Affaires étrangères, demande même aux Allemands de bombarder Arkhangelsk et d'attaquer la voie de Mourmansk, mais à condition d'éviter Petrograd ${ }^{70}$. Cette position soviétique peut apparaître étrange. En fait, elle est pragmatique. Les bolcheviks, isolés suite à la défection des socialistes-révolutionnaires de gauche et menacés de toutes parts, n'ont pas les moyens de reconquérir la voie de Mourmansk. Ils préfèrent donc la voir aux mains d'un pays ayant signé un accord avec eux qu'en celles d'un État apparemment plus hostile. Lénine a insisté d'ailleurs fortement au printemps sur la nécessité de trouver des solutions pour stabiliser la situation le long de la frontière avec la Finlande. Le 6 mai, il a préconisé devant le comité central du PC(b)R

65 KA, A.A, Bd 7, L 082229-082230, 25 mai 1918.

66 KA, fonds J. K. Paasikivi, K. III : 10.

67 Hannu Salokorpi, Pietarin tie..., op. cit., p. 247-248.

68 KA, A.A., Bd 7, L 082204, télégramme du 30 mai 1918.

69 Tuomo Polvinen, op. cit., t. II, Toukokuu 1918-joulukuu 1920 (Mai 1918-décembre 1920), p. 46. Ce chercheur fait ici référence à un fonds conservé par les Archives de guerre (Sota Arkisto) : «OstseeDivision. Kriegstagebuch des Stabes 08/08/1918 - 19/08/1918».

70 Ibid. 
de mener des pourparlers avec le représentant allemand Wilhelm von Mirbach afin qu'il encourage les Finlandais à conclure une paix avec la Russie, même au prix d'annexions supplémentaires. Il est en effet persuadé (à tort) que c'est Berlin qui a poussé Helsinki à attaquer le fort d'Ino et la voie de Mourmansk ${ }^{71}$. La réponse ne tarde pas : le 8 mai, les Allemands exigent de rendre le fort d'Ino, ce qui est accepté ; comme il n'est pas précisé dans quel état, la garnison le quitte le 14 après avoir détruit tout ce qu'elle peut. Ce jour-là, lors d'une réunion entre le comité central du parti et les représentants du soviet de Moscou, Lénine dénonce vivement les intrigues britanniques dans la région de Mourmansk ${ }^{72}$. Le 26 juin, toujours angoissé par l'instabilité aux frontières, il laisse entendre dans un télégramme à Ioffé et Menjinski qu'il " donnerait cher pour obtenir une paix avec la Finlande, l'Ukraine et la Turquie ${ }^{73}$. Il est donc clair que la priorité des bolcheviks n'est pas, pour le moment, de sanctuariser leur territoire, mais de stabiliser la situation intérieure. Une fois la guerre civile commencée en juillet, l'impératif est de parer au plus pressé en lâchant du lest pour réduire la probabilité d'une intervention extérieure hostile.

Du côté des autorités de Helsinki, la position est apparemment plus offensive. Lors d'une réunion de l'intergroupe droite-agrariens (Yhteinen Delegatsioni), le 19 juin 1918, Svinhufvud déclare : «Le gouvernement considère comme sa tâche principale la création de la Grande Finlande. Mais cela ne peut intervenir que si la monarchie est implantée en Finlande et si nous obtenons d'avoir un roi allemand. Si c'est la République, les finances seront affaiblies. Il y aura de l'agitation dans l'armée. Or, l'aide des Allemands dépend essentiellement du monarque et de leur confiance à notre égard. "Il est cependant conscient que l'opposition du SPD pose problème. Son ministre Paasikivi est lui aussi d'avis que les Allemands ne souhaitent pas briser la paix de Brest-Litovsk, mais reste persuadé qu'ils peuvent les aider à améliorer les contours de la frontière orientale ; il souligne à ce propos, détail révélateur, que Petsamo n'a pas « de grande signification pour la Finlande ", mais que la question de Carélie du Sud est vitale, suggérant ainsi qu'il ne faut pas faire d'échange de territoires dans cette zone. Répondant à une question sur l'ouverture de négociations avec les Russes depuis la fin mai 1918, il considère qu'elles ne sont qu'un pis-aller et qu'on n'obtiendra pas ce qui est souhaitable. Ces considérations à connotation guerrière inquiètent Ståhlberg qui fait observer qu' " avec de vagues espoirs, on ne peut régler une question aussi importante que celle du mode de gouvernement $»^{74}$.

71 Lénine, Euvres complètes, op. cit., t. XXVII, p. 371.

72 Ibid., p. 398.

73 Lénine, Euvres complètes, op. cit., t. XLIV, p. 67-68.

74 Notes d'Ernst Erlander à ladite réunion, citées par Aappo Kähönen et Kauko Rumpunen (dir.), Itsenäisyyden muotoilijat (Ceux qui donnèrent forme à l'indépendance), Helsinki, Edita, 2008, p. 237-238, 240 et 243. 
Pour réaliser leurs rêves de conquête, le gouvernement finlandais manque toutefois de l'instrument essentiel, à savoir une armée performante. Un rapport de von der Goltz la juge incapable de mener une opération de grande envergure à l'est : une partie de la troupe est peu motivée, l'intendance laisse à désirer, la nourriture est exécrable et la qualité individuelle des combattants ne peut compenser l'absence d'expérience d'une partie de l'encadrement ${ }^{75}$. C'est pourquoi le commandement militaire allemand répond favorablement à une demande finlandaise portant sur l'envoi de quelques dizaines d'officiers instructeurs qui s'empressent de peupler les bureaux de l'état-major et des principales unités ${ }^{76}$. Mais à partir d'août 1918, l'Allemagne, en difficulté sur le front occidental, est de moins en moins capable de dicter sa loi dans la région.

Les monarchistes finlandais, échaudés également par quelques cachotteries de leur alliép ${ }^{77}$, en rabattent un peu et se préoccupent surtout désormais de faire venir en Finlande celui qu'ils espèrent voir devenir leur roi : Frédéric de Hesse. L'aventure à l'est ne leur parait plus aussi urgente au vu de la nouvelle conjoncture. Ils échafaudent même des plans alternatifs ; ils vont jusqu'à envisager une union politique avec l'Estonie ${ }^{78}$ que les sociaux-démocrates finlandais avaient eux aussi envisagée quelques mois plus tôt $t^{79}$. Tout est bon en fait pour empêcher leurs adversaires politiques de reprendre la main à l'occasion d'une défaite allemande de plus en plus probable.

\section{NOVEMBRE 1918 - NOVEMBRE 1919 : LES TENSIONS À LEUR PAROXYSME}

L'effondrement rapide du Reich reconfigure le contexte général. La guerre civile en Russie semble un temps tourner à l'avantage des adversaires des bolcheviks ${ }^{80}$; ces derniers ne parviennent à redresser la barre qu’à l'automne 1919; obligés de se battre sur plusieurs fronts, ils ont bien du mal à contenir les assauts des armées blanches et échouent dans leur tentative de reprendre pied dans les anciennes provinces baltes où les nationalistes parviennent à déclarer l'indépendance ${ }^{81}$. Les puissances alliées interviennent massivement en Russie jusqu'à l'été 1919 aux côtés des blancs tandis que la Navy tient le haut du pavé en Baltique, ce qui oblige Svinhufvud à démissionner dès décembre 1918 et son successeur, l'archevêque Ingman, à renouer de meilleures relations avec Londres et Paris. En Finlande, les monarchistes sont largement battus aux élections législatives de mars, puis

75 Seppo et Marjaliisa Hentilä, Saksalainen..., op. cit., p. 278.

76 Ibid., p. 274 sq.

77 Ibid., p. 284-285.

78 Jukka-Pekka Pietiäinen, Rudolf Holsti..., op. cit., p. 327.

79 Maurice Carrez, La fabrique..., op. cit., t. II, chap. XI.

80 Evan Mawdsley, The Russian..., op. cit., chap. IX à XIV, p. 157-298; Jean-Jacques Marie, La guerre des..., op. cit., chap. VI à XV, p. 159-261.

81 Jean-David Avenel, Pierre Giudicelli, Lindépendance des pays de la Baltique. 1918-1920, Paris, Économica, 2004 [pour les aspects militaires seulement]. 
aux présidentielles de juillet 1919, ce qui n’est pas sans répercussions sur la ligne diplomatique.

Ayant senti venir le vent dès l'été 1918, le baron Mannerheim, qui a pris opportunément ses distances avec l'équipe Svinhufvud, essaie à l'automne de sauver la cause monarchiste en amadouant les puissances alliées. Il arrive dès le 12 novembre 1918 à Londres afin d'éviter que son pays ne soit considéré à la future conférence de paix comme un État vaincu ${ }^{82}$. Son passé de général du tsar lui donne pour ce faire une réelle supériorité sur l'ancien gouvernement qui, conscient de son lourd handicap, prend d'ailleurs contact avec lui le 17 novembre ${ }^{83}$. Le général baron peut espérer en cas de succès devenir le nouvel homme fort d'Helsinki. Or, sur la question carélienne, il est loin d'être modéré, au point d'être soupçonné, par certains historiens, d'avoir voulu devenir celui qui sauverait la Russie du bolchevisme ${ }^{84}$.

Côté russe aussi, les choses se précipitent. En octobre 1918, Zinoviev appelle les ressortissants finnois présents à Petrograd et dans sa région à se signaler auprès des autorités militaires de l'Armée rouge ${ }^{85}$; le gouvernement Svinhufvud y lit aussitôt une mesure hostile et demande son aide à la diplomatie allemande ; celle-ci accepte de jouer l'entremetteur et obtient de Karachan, l'adjoint de Tchitcherine, une réponse embarrassée assortie de la promesse d'essayer de calmer le jeu ${ }^{86}$. Les bolcheviks profitent néanmoins du retrait allemand pour regagner des positions : Zinoviev réunit ainsi début janvier 1919 trois dirigeants rouges finlandais afin de mettre au point un plan d'attaque contre la Finlande «blanche ${ }^{87}$, plan qui ne verra en fait jamais le jour ; l'Armée rouge, appuyée par des unités de bolcheviks autochtones, s'efforce quant à elle de reprendre le terrain perdu dans les pays baltes. Dès le 22 novembre 1918, elle lance l'assaut contre Narva, prise quelques jours plus tard ; fin décembre, elle occupe une grande partie de l'Estonie et de la Lettonie tout en avançant en Lituanie ${ }^{88}$. Les généraux russes blancs sont également actifs. Nikolaï Ioudenitch, réfugié à Helsinki avec sa famille, prend contact fin novembre avec l'état-major finlandais et les représentants britanniques pour qu'ils l'aident à préparer la revanche ; à ces derniers, il demande de faire pression sur le gouvernement autochtone afin qu'il lui apporte son soutien pour attaquer Petrograd. Mais son refus, à deux reprises, de confirmer officiellement l'indépendance finlandaise rend ce scénario impossible. Il se tourne alors vers le

82 Jukka-Pekka Pietiäinen, Rudolf Holsti..., op. cit., p. 327-331.

83 Einar W. Juva, P. E. Svinhufvud, t. II, op. cit., p. 283.

84 Ibid., p. 210 ; Jean-Jacques Fol, Accessio..., op. cit., t. II, p. 865, 888-889, 896, 907.

85 KA, A.A., Bd 19, traduction de l'ordre de Zinoviev en allemand, 15 octobre 1918.

86 KA, A.A., Bd 19, télégramme de von Brück à Stenrooth, nouveau ministre finlandais des Affaires étrangères, 7 novembre 1918 .

87 Markku Kangaspuro, Neuvosto-Karjalan taistelu..., op. cit., p. 71.

88 Jean-David Avenel, Pierre Giudicelli, Lindépendance..., op. cit., p. 110, 112, 120. 
gouvernement nationaliste estonien qui a davantage besoin de l'aide anglaise et accepte de soutenir une éventuelle offensive sur Petrograd depuis Narva ${ }^{89}$. Probablement, Ioudenitch et les Estoniens ont eu vent que des réfugiés ingres avaient demandé aux autorités d'Helsinki de soutenir un soulèvement antibolchevique dans leur région ${ }^{90}$, ce qui est de nature à renforcer leur détermination. Quoi qu'il en soit, le gouvernement finlandais reste plutôt prudent dans cette affaire comme le prouvent les tractations entre les Ingres et le ministre des Affaires étrangères Carl Enckell à la fin décembre ${ }^{91}$. Mais il s'agit plus de realpolitik que d'une vraie volonté d'apaisement : le refus des Russes blancs, notamment Koltchak et Denikine $^{92}$, de reconnaître l'indépendance incite Helsinki à ne pas trop favoriser leurs plans, d'autant que les autorités et les partis vainqueurs de la guerre civile, en particulier les agrariens et les activistes, sont obsédés par la présence de nombreux russes émigrés dans les départements de Vyborg et de l'Uusimaa (Helsinki) ${ }^{93}$; néanmoins, la volonté de nuire aux bolcheviks est toujours là, comme le prouve le rapport envoyé à Rudolf Holsti par le ministère des Affaires étrangères le 10 décembre $1918^{94}$. Le général Ioudenitch ne s'y trompe pas quand il télégraphie à Koltchak le 21 janvier 1919 qu'il croit toujours possible de créer, avec l'aide des Alliés, un front commun entre lui, les Estoniens et les Finlandais contre les nouveaux maîtres du Kremlin ${ }^{95}$. Ces manœuvres n'échappent pas aux bolcheviks, au point que Zinoviev, décidément très vindicatif, dans un article remarqué de la Pravda, demande début février 1919 un renforcement de la défense de Petrograd, concrétisé un peu plus tard par l'arrivée sur place de Trotski ${ }^{96}$. Mais ce dernier, tout en mettant en garde Helsinki contre une intervention militaire, rappelle

89 Jean-Jacques Marie, La guerre des..., op. cit., p. 213-214.

90 Pekka Nevalainen, Rautaa Inkerin rajalla..., op. cit., p. 42. Ladite demande est envoyée le 24 novembre 1918.

91 Tuomo Polvinen, op. cit., t. II, p. 227. À ce sujet, il y a aux archives centrales du ministère des Affaires étrangères (UMA, 11 II : 1), une lettre très intéressante des Ingres à Carl Enckell datée du 20 décembre 1918.

92 Jean-Jacques Fol, Accession..., op. cit., t. II, p. 728 ; il signale que Ioudénitch est plus ouvert, mais par simple opportunisme.

93 UMA, Fl 12, L 12, liasses (par années) : "Venäläiset pakolaiset ja heidän avustamisensa » ("Les réfugiés russes et l'aide qui leur est accordée »). Si la crainte d'y voir figurer des éléments rouges déguisés est forte, la critique des éléments conservateurs, voire " réactionnaires ", est tout aussi présente.

94 UMA, Fl 12, L 12, "Herra Senaattori Holsti », 10 décembre 1918. Le document mentionne les discussions avec le groupe réactionnaire dirigé par l'ancien ministre russe Trepow et le duc évêque Wolkonsky à propos de la création d'une troupe de volontaires russes antibolcheviques ; il évoque aussi la lutte intense contre la propagande communiste en Finlande et sur la Baltique.

95 Jean-Jacques Marie, La guerre de..., op. cit., p. 215. Il est à noter que, selon Mannerheim, le consul français à Helsinki l'aurait assuré le 25 janvier que le gouvernement français poussait les Russes blancs à reconnaitre l'indépendance finlandaise pour favoriser un front antibolchevique : Gustaf Mannerheim, op. cit., p. 398.

96 Tuomo Polvinen, op. cit., t. II, p. 161-163. 
que le Commissariat du peuple est disposé à avoir des relations apaisées avec la Finlande ${ }^{97}$.

Cet appel du pied n'a guère d'effet. Les défaites bolcheviques sur le front balte ${ }^{98}$ laissent au contraire croire que les dirigeants de Moscou sont aux abois et cherchent à gagner du temps. Les activistes finlandais et les nationalistes caréliens poussent par ailleurs à une intervention militaire, encouragés ouvertement par l'Union agraire (Maalaisliitto) : dans son carnet, Santeri Alkio, son principal dirigeant, note le 25 février 1919 avec jubilation que le Comité pour la conquête de la Carélie d'Olonets (Vienan Karjalan valtauskomitea) préconise une attaque simultanée en Carélie et en Ingrie ${ }^{99}$. Les agrariens sont également en pointe sur la question des réfugiés russes et n'hésitent pas en plein Parlement à accuser le gouvernement Ingman de "russophilie ${ }^{100}$. C'est dans ce contexte tendu qu'un congrès de nationalistes caréliens, tenu du 16 au 19 février 1919, proclame la Carélie État indépendant et revendique un territoire allant de la rivière Svir et du Ladoga au sud jusqu’à la mer Blanche à l'est et la mer de Barents au nord ${ }^{101}$. Quelques jours plus tard, une délégation carélienne arrive à Paris et demande à être reçue à la conférence de la Paix ${ }^{102}$. Ces événements amènent les groupes ultranationalistes à multiplier les provocations sur le terrain ; ainsi, des saboteurs liés aux activistes s'attaquent fin mars à une station de pompage de Petrograd et allument des incendies faisant de nombreuses victimes dans la ville ${ }^{103}$. Lénine a beau clamer le 19 mars 1919 devant le VIII ${ }^{e}$ congrès du PC(b)R que l'indépendance de la Finlande "s'impose d'elle-même » ${ }^{104}$, le gouvernement Ingman, malgré les réserves de son chef, décide de soutenir l'expédition militaire programmée par les activistes au vu et au su de tous ${ }^{105}$. La demande du Kremlin, le 14 avril 1919, d'ouvrir des négociations sur la frontière ne fait même pas l'objet d'une réponse ${ }^{106}$. Au demeurant, trois jours plus tard, Lauri Ingman, mis sur la sellette lors du débat parlementaire du 11 avril par des agrariens déchaînés ${ }^{107}$ et jugé trop

97 Pravda, 13 février 1919.

98 Jean-David Avenel, Pierre Giudicelli, Lindépendance..., op. cit., p. 11, 119, 121.

99 Pour l'attitude d'Alkio en janvier-février 1919 et ses vues sur Petrograd, voir Aulis J. Alanen, Santeri Alkio, Porvoo - Helsinki, WSOY, 1976, p. 538-539.

100 Valtiopäivät 1918 (VP 1918 : séances parlementaires 1918, en fait jusqu'en avril 1919, date de l'élection d'une nouvelle assemblée), p. 331-332 (10 janvier 1919 : interpellation du Gouvernement sur la question des réfugiés russes) et p. 384-401 (débat parlementaire du 17 janvier 1918 à ce propos).

101 La résolution finale est citée dans David G. Kirby, Finland and Russia 1808-1920. From Autonomy to Independence. A Selection of Documents, Londres, Macmillan, 1975, p. 248-249.

102 Jean-Jacques Fol, Accession..., op. cit., t. II, p. 767-768.

103 Pekka Nevalainen, Rautaa Inkerin rajalla..., op. cit., p. 54.

104 Lénine, Euvres complètes, op. cit., t. XXIX, p. 194.

105 Hannu Salokorpi, Pietarin tie..., op. cit., p. 289.

106 Tuomo Polvinen, op. cit., t. II, p. 165.

107 VP 1919, séance du 11 avril 1919, p. 42 sq. 
réservé vis-à-vis d'une épreuve de force ${ }^{108}$, est remplacé à la tête du gouvernement par Kaarlo Castrén disposé, lui, à l'assumer, au nom « de l'inexistence de fait d'un état de paix " entre la Russie et la Finlande ${ }^{109}$. L'aventure est tentante d'autant qu'un accord vient d'être signé fin mars entre les Estoniens et les nationalistes ingres pour que ces derniers puissent fonder un régiment autonome équipé par l'armée de Laidoner en prévision d'un assaut final contre Petrograd ${ }^{110}$. Cela dit, des voix discordantes se font entendre : il n'est guère étonnant d'y retrouver les sociaux-démocrates finlandais qui, revenus en force au Parlement ${ }^{111}$, sont à l'origine de l'interpellation et du débat du 11 avril ; plus surprenant est de constater qu'un activiste aussi convaincu que l'historien et diplomate Herman Gregorius Gummerus, futur fondateur du Mouvement de Lapua, prône la prudence dans un rapport daté lui aussi du 11 avril et envoyé à sa tutelle. Pour lui, les Russes sont quasi génétiquement impérialistes, quel que soit le parti, mais ce serait « un pas inquiétant " que de partir en guerre pour venir en aide aux nationalistes caréliens. Il estime flottant le soutien des Alliés comme de celui des Allemands et juge que le seul moyen de pression efficace sur la Russie serait la formation d'une sorte de Ligue des États périphériques et des pays du Nord. À terme, il pense qu’il faudra avoir des rapports apaisés avec le grand voisin une fois l'indépendance assise, ne serait-ce que pour des raisons économiques (il est entre autres le représentant du cartel du papier en Ukraine) ${ }^{112}$.

Mais il est sans doute trop tard pour empêcher les plus ardents de faire le contraire. Le représentant allemand à Helsinki, von Brück, le note avec inquiétude dans une missive qu'il envoie à sa hiérarchie le 25 mars 1919 avec la traduction de l'article du professeur Grotenfelt dans Uusi Suomi ${ }^{113}$. Dans la nuit du 20 au 21 avril, 3000 volontaires finlandais franchissent donc la frontière et se dirigent derechef sur Olonets (Aunus) ; l'objectif est clair : s'emparer de la Carélie

108 Lauri Ingman, bien qu’anticommuniste viscéral et monarchiste convaincu (jusqu'en 1919 au moins), n'est pas persuadé qu'une expédition militaire en Carélie s'impose pour le moment : figure désormais de l'aile "modérée " de la droite nationaliste, il est conscient des limites de l'armée finlandaise et de la nécessité d'agir prudemment, sans heurter les intérêts des Alliés, ne serait-ce que pour qu’ils reconnaissent de nouveau l'indépendance finlandaise. Il a accepté d'envoyer 4000 volontaires au secours de l'Estonie, mais dans un cadre strict avec retour prévu dès que possible : Vesa Vares, Vanhasuomalainen Lauri Ingman ja hänen politttinen toimittansa (Le vieux-finnois Lauri Ingman et son action politique), Helsinki, Juva, 1996, p. 178-203 ; id., Konservatiivi ja murrosvuodet. Lauri Ingman ja hänen poliittinen toimintansa vuoteen 1922 (Un conservateur face aux années de bouleversement. Lauri Ingman et son action politique jusquien 1922), Helsinki, SHS, 1993, p. 427-434, 443-446.

109 Jean-Jacques Fol, Accession..., op. cit., t. II, p. 726.

110 Tuomo Polvinen, op. cit., t. II, p. 228-229.

111 Les élections de mars 1919 leur permettent de redevenir le premier parti de Finlande avec près de $40 \%$ des voix malgré les séquelles de la guerre civile.

112 UMA, Fl 12, 12 L, "Venäjä 1919 » (Russie 1919) : rapport intitulé Suomen subtautuminen Venäjään (L'orientation de la Finlande par rapport à la Russie), 11 avril 1919.

113 KA, A.A., Bd 21, L 083223-083224, lettre de von Brück à la Deutsche Gesandtschaft, 25 mars 1919. 
et l'annexer à la Finlande ${ }^{114}$. Si le gouvernement finlandais n'a pas officiellement envoyé de troupes, il prend la responsabilité de faciliter la tâche de ces activistes ; le 25 avril, le ministre des Affaires étrangères envoie à Rudolf Holsti, toujours à Londres, la consigne d'inciter les Britanniques à envoyer la Royal Navy patrouiller le long des côtes du golfe de Finlande ${ }^{115}$. Deux jours plus tard, Gueorgui Tchitcherine envoie une note de protestation contre la violation caractérisée de la frontière, assortie d'une menace d'utiliser la classe ouvrière finlandaise contre la politique agressive menée par son gouvernement ${ }^{116}$. Cette démarche n'impressionne pas Castrén. D'ailleurs, et bien qu'ils mettent en garde contre les effets que pourraient avoir une attaque contre Petrograd et des revendications trop affirmées sur la Carélie ${ }^{117}$, les Alliés, qui reconnaissent définitivement l'indépendance début mai 1919, se montrent peu empressés à prendre des mesures concrètes contre l'activisme finlandais, au grand dam de Ioudenitch. Or, diverses manœuvres sont à l'œuvre pour relancer l'agitation en Ingrie où la politique bolchevique de réquisitions et d'enrôlements provoque des résistances : des contacts sont pris entre Mannerheim, les nationalistes ingres et les activistes afin de hâter un soulèvement dans la partie nord de la province ${ }^{118}$. Fin mai 1919, l'état-major finlandais met la dernière main à un projet d'attaque contre Petrograd alors que les activistes se déchaînent le long de la frontière pour provoquer un conflit ouvert ${ }^{119}$. Parallèlement, le colonel Georg Elfvengren est en passe de prendre la direction d'un régiment de 580 recrues volontaires pour " défendre " la république de Kirjasalo, une étroite bande de terre gagnée par les nationalistes à la frontière de l'Ingrie ; or, celui-ci est connu pour ses sympathies envers les généraux blancs russes et sa poigne brutale envers les « rouges », déjà manifestée à l'époque de la guerre civile ${ }^{120}$. On est à deux doigts d'une guerre en bonne et due forme, comme le prouvent les protestations rageuses envoyées par Tchitcherine d'un côté et Ehrnrooth de l'autre entre fin mai et début juin ${ }^{121}$. Sans même prévenir ses collègues, ce dernier, alors adjoint du ministre des Affaires étrangères, envoie même le 7 juin au Commissariat du peuple une note tellement menaçante qu'elle déclenche, lorsqu'elle est connue, l'ire du Helsingin Sanomat, journal pourtant peu suspect de sympathie envers les bolcheviks ${ }^{122}$, de même que celle de Santeri Alkio qui parle de

114 Jussi Niinistö, Heimosotien..., op. cit., chap. V, p. 148-183.

115 Tuomo Polvinen, op. cit., t. II, p. 229.

116 Ibid., p. 165-166.

117 Jean-Jacques Fol, Accession..., op. cit., t. II, p. 768-772 les a bien décrites, mais il surestime de mon point de vue leur impact.

118 Pekka Nevalainen, Rautaa Inkerin rajalla..., op. cit., p. 69-71.

119 Ibid., p. 65.

120 Jean-Jacques Marie, La guerre des Russes blancs..., op. cit., p. 216.

121 UMA, Fl 12, 12 L, "Venäjä 1919 " (Russie 1919) : télégrammes des 21 mai, 23 mai, 5 juin et 7 juin 1919 ; Jean-Jacques Fol, Accession..., op. cit., t. II, p. 773.

122 Jukka-Pekka Pietiäinen, Rudolf Holsti..., op. cit., p. 388-389. 
provocation ${ }^{123}$. Les Soviétiques, lassés de ces avanies et décidés cette fois à défendre Petrograd, montrent aussi les dents : le 9 juin 1919, deux de leurs torpilleurs attaquent la flotte britannique au large du golfe de Vyborg. Du coup, le 11 juin 1919, le gouvernement Castrén discute à son tour d'une éventuelle intervention en direction de l'ancienne capitale russe et d'une aide directe aux nationalistes ingres ; il est néanmoins divisé sur la question et la montagne accouche d'une souris $^{124}$. Mais les troupes du général Mikhaïl Rodzianko, parties le 13 mai 1919 de Narva, parviennent le 13 juin, grâce à une trahison et avec l'appui de régiments estoniens et d'un bataillon ingre, à faire tomber l'un des derniers forts défendant Petrograd sur la rive méridionale du golfe de Finlande, Krasnaïa Gorka ${ }^{125}$.

Mais une contre-attaque foudroyante de l'Armée rouge à partir du 15 juin 1919 provoque la déroute rapide de l'armée de Rodzianko qui en quelques semaines est ramené à son point de départ ${ }^{126}$. En outre, le 27 juin, un audacieux coup de main dirigé par un ancien chef des Gardes rouges finlandais, Eino Rahja, aboutit à la destruction du centre de ravitaillement du corps expéditionnaire d'Aunus installé près du village de Vitele, sur les rives du Ladoga ; les blancs doivent refluer rapidement ${ }^{127}$. En pleine campagne des élections présidentielles, le gouvernement Castrén est donc momentanément condamné à l'attentisme, encouragé en cela par son homologue britannique qui doute de la capacité des Finlandais à conquérir Petrograd tout en craignant une victoire de Mannerheim, partisan de la manière forte, auxdites élections ${ }^{128}$. Se dirige-t-on dès lors vers un apaisement, comme pourraient le faire penser une nouvelle offre de paix envoyée le 11 juillet 1919 aux autorités d'Helsinki par les Soviétiques ${ }^{129}$ ainsi que le retrait des Alliés hors de Russie et d'Ukraine?

Rien n'est moins sûr car les manœuvres continuent en coulisse. Mannerheim essaie toujours de convaincre les chefs des partis de droite, hésitants, de ne pas renoncer à la conquête de Petrograd en dépit des vents contraires ${ }^{130}$. Sa défaite, le 25 juillet à l'élection présidentielle face au républicain Kaarlo Juho Ståhlberg, le met toutefois hors-jeu. Mais le colonel Elfvengren, devenu la veille chef du contingent ingre de Kirjasalo, prend le relais et se lance dans une attaque frontale sur l'Ingrie du Nord où ses troupes se livrent au pillage et à des exécutions

123 Jean-Jacques Fol, Accession..., op. cit., t. II, p. 774.

124 Jukka-Pekka Pietiäinen, Rudolf Holsti..., op. cit., p. 389.

125 Jean-Jacques Marie, La guerre des Russes blancs..., op. cit., p. 217-223.

126 Tuomo Polvinen, op. cit., t. II, p. 233-234.

127 Jussi Niinistö, Heimosotien..., op. cit., chap. V, p. 176-183.

128 Pekka Nevalainen, Rautaa Inkerin rajalla..., op. cit., p. 43. Les diplomates britanniques considèrent Mannerheim comme un réactionnaire belliciste.

129 Tuomo Polvinen, op. cit., t. II, p. 238.

130 Pekka Nevalainen, Rautaa Inkerin rajalla..., op. cit., p. 66 ; Hannu Salokorpi, Pietarin tie..., op. cit., p. 292. 
sommaires ${ }^{131}$. Il est toutefois vite refoulé sur Kirjasalo par les bolcheviks, ce qui entraîne la fuite de nombreux civils craignant des mesures de rétorsion. Quant au général Nikolaï Ioudenitch, il part dès l'élection de Ståhlberg vers l'Estonie, car il est décidé à reprendre le flambeau éteint de Rodzianko avec, entre autres, une division bolchevique ayant trahi les siens, comme c'est alors assez fréquent. Il dispose de fonds non négligeables et sait qu'en cas de réussite d'une offensive, il recevra l'appui de Tallinn et des capitales alliées ${ }^{132}$. En attendant, les responsables finlandais sont perplexes, le président de la République et certains chefs de la droite, comme Paasikivi, ne souhaitant pas s'engager à la légère. Sentant un certain flottement à Helsinki et dans les capitales baltes, les bolcheviks tentent de nouveau le 31 août 1919 de proposer la paix aux États limitrophes ${ }^{133}$. C'est sans doute la raison qui pousse Mannerheim à réagir deux semaines plus tard : le général blanc, résigné à quitter son ingrate patrie, fait une longue déclaration publique dans laquelle il incite son pays à combattre sans relâche le bolchevisme ${ }^{134}$. De son côté, Ioudenitch hâte les préparatifs de l'attaque qu'il projette contre Petrograd.

Le mois d'octobre est ainsi marqué par le regain des combats. Le 7, les 18500 hommes de l'armée blanche de Ioudenitch quittent Narva et envahissent l'Ingrie sans rencontrer de résistance très organisée ${ }^{135}$. Ils sont rejoints le 11 par des régiments estoniens et ingres, tandis que le 12, Elfvengren, en accord avec le commandant en chef russe et avec l'approbation tacite de l'état-major finlandais, tente une nouvelle attaque depuis Kirjasalo que les bolcheviks ont échoué à reprendre deux semaines plus tôt $\mathrm{t}^{136}$. L'offensive semble presque irrésistible : le 16, les russes blancs sont à Gatchina, à 40 kilomètres du centre de Petrograd. Ioudenitch, sûr de sa victoire et vexé des avanies qu'il avait jadis subies à Helsinki, se paie le luxe d'exiger sur un ton comminatoire que l'armée finlandaise reste l'arme au pied ${ }^{137}$ alors qu'elle se prépare à déferler sur Petrograd. Finalement, le refus britannique d'accorder un prêt la force à renoncer à ce projet ${ }^{138}$. Mais moins d'une semaine plus tard, le 22, le général russe blanc, qui rencontre une résistance acharnée, opère un spectaculaire revirement et supplie le général français Étiévant de convaincre les troupes finlandaises d'attaquer la grande métropole ${ }^{139}$ ! Le 28 octobre, Mannerheim écrit à Ståhlberg pour qu'il donne enfin l'ordre

131 Pekka Nevalainen, Rautaa Inkerin rajalla..., op. cit., p. 82-87.

132 Le général britannique Gough vient dès le 7 août dans la capitale estonienne pour convaincre les Estoniens, un peu échaudés par l'échec de Rodzianko, d'appuyer Ioudenitch : Tuomo Polvinen, op. cit., t. II, p. 247.

133 Ibid., p. 255 sq. ; Pekka Nevalainen, Rautaa Inkerin rajalla..., op. cit., p. 117.

134 Gustaf Mannerheim, Muistelmat, op. cit., p. 441-44.

135 Jean-Jacques Marie, La guerre des Russes blancs..., op. cit., p. 279, parle du 10 octobre, mais il semble avoir commis une petite erreur.

136 Pekka Nevalainen, Rautaa Inkerin rajalla..., op. cit., p. 116, 124-125.

137 Jean-Jacques Marie, La guerre des Russes blancs..., op. cit., p. 281.

138 Pekka Nevalainen, Rautaa Inkerin rajalla..., op. cit., p. 126.

139 Jean-Jacques Marie, La guerre des Russes blancs..., op. cit., p. 283-284. 
d'attaquer ${ }^{140}$. Mais celui-ci a compris que les bolcheviks sont en passe de remporter la bataille et se garde bien d'obtempérer. En novembre 1919, les Russes blancs et leurs alliés refluent déjà en désordre vers Narva. Seul Elfvengren, totalement isolé et accusé par les activistes finlandais d'être à la solde des généraux russes, lance encore quelques raids sans lendemain à la frontière de l'Ingrie. Le 22 novembre 1919, Lénine peut ainsi déclarer devant le deuxième congrès des organisations communistes des peuples d'Orient que l'offensive "impérialiste " par petits pays voisins interposés a lamentablement échoué, sans risque d'être contredit ${ }^{141}$. La droite finlandaise n'est pas encore totalement résignée puisqu'elle discute encore à la mi-décembre d'un éventuel assaut sur Petrograd, mais son moral est en berne et elle est de plus en plus divisée sur la question ${ }^{142}$. Les diplomates quant à eux sont persuadés qu'une aide militaire des Alliés est désormais une chimère ${ }^{143}$. La route est ouverte à des négociations bipartites.

\section{DÉCEMBRE 1919 - JUIN 1922 : \\ REPRISE DU DIALOGUE ET CONFLITS SPORADIQUES}

La situation internationale est considérablement modifiée. Les principales armées blanches russes sont écrasées une à une entre la fin 1919 et l'automne 1920 par l'Armée rouge ${ }^{144}$. Et bien que celle-ci soit encore en difficulté entre août et octobre 1920 face aux Polonais ${ }^{145}$ et mobilisée ensuite par des soulèvements paysans (les armées "vertes " ${ }^{146}$ ) récurrents, le pouvoir bolchevique sort renforcé de la guerre civile, d'autant qu'il signe toute une série de traités de paix avec ses voisins immédiats. Les principaux pays européens ont établi " un cordon sanitaire » autour de la Russie, mais ils doivent aussi tenir compte, comme les États limitrophes, de ce renouveau de la puissance russe, même si cela ne va pas de soi pour de nombreuses formations politiques qui ont fait de l'antibolchevisme une marque de fabrique.

Bien que des accrochages sérieux aient eu lieu entre des unités de l'Armée rouge et des soldats finlandais en février-mars dans la zone de Repola et Porajärvi ${ }^{147}$, le gouvernement finlandais adresse pour la première fois en mars 1920 une lettre aux autorités bolcheviques à propos de ce qu'il nomme la "ligne de démarcation ";

140 Gustaf Mannerheim, Muistelmat, op. cit., p. 451-452.

141 Lénine, Euvres complètes, op. cit., t. XXX, p. 156.

142 Hannu Salokorpi, Pietarin tie..., op. cit., p. 292-293.

143 UMA, Fl 12, 12 L, «Venäjä 1919» (Russie 1919) : rapport de H. G. Gummerus sur sa rencontre à Rome avec Sir Buchanan, 3 décembre 1919.

144 Evan Mawdsley, The Russian..., op. cit., chap. XV-XVII, p. 301-344 ; Jean-Jacques Marie, La guerre des..., op. cit., chap. XIV à XVI, p. 309-406.

145 Evan Mawdsley, The Russian..., op. cit., chap. XVIII, p. 345-361.

146 Jean-Jacques Marie, Histoire de..., op. cit., chap. X, p. 297-370.

147 Jussi Niinistö, Heimosotien..., op. cit., chap. VII, p. 214-216. La zone est occupée depuis 1918 par les Finlandais et sert de refuge à de nombreux Russes blancs. 
elle fait suite à une proposition de compromis de Rudolf Holsti envoyée à Tchitcherine ${ }^{148}$. Malgré son caractère un peu abrupt, Lénine veut y voir une sorte de proposition de paix qui ne dit pas son nom ; il le déclare en tout cas devant le IX congrès du PC(b)R début avril $1920^{149}$. Les Britanniques, qui ont décidé de quitter la zone de Mourmansk, poussent désormais en ce sens, au point que le 12 avril, de vraies négociations bipartites s'ouvrent sur les rives de la Sestra (Rajajoki), une petite rivière qui sert de frontière entre les deux États. Elles durent jusqu'au 24 avril avant d'achopper sur deux points : l'évacuation par les Finlandais de Repola et Porajärvi (exigée par les Russes) ainsi que l'établissement d'une zone neutralisée en Carélie (demandé par les Finlandais) ${ }^{150}$. Les deux localités précitées, ayant chacune une grande superficie, sont connues pour leurs ressources forestières : cela peut expliquer la raideur des négociateurs finlandais à leur endroit. Mais on peut aussi évoquer le fait que les gouvernements polonais et finlandais négocient au même moment (entre le 4 et le 24 avril) une alliance "défensive ", dirigée de fait contre les Russes. Le refus de la partie soviétique de céder sur le second point est sans doute lié au fait que des discussions préalables ont eu lieu entre les dirigeants bolcheviques et Edvard Gylling pour fonder une république autonome de Carélie au sein d'une Russie communiste et fédérale, dans l'espoir d'en faire éventuellement une base de départ pour l'extension ultérieure de la révolution prolétarienne à l'échelle de toute la Fennoscandie ; l'ancien dirigeant social-démocrate devenu communiste, qui a quitté Stockholm pour rejoindre Moscou le 17 avril 1920, a eu à ce sujet des tractations épistolaires avec Lénine ${ }^{151}$. Il est possible également que les bolcheviks de Petrograd aient fait pression en faveur de la fermeté, car ils craignent pour leur propre sécurité. Quoi qu'il en soit, du fait de ces désaccords, la tolérance momentanée et relative des bolcheviks envers les activités du Comité de la Carélie blanche (Vienan Karjalan toimikunta) prend fin. Celui-ci a pu réunir une sorte d'assemblée provinciale à Uhtua (Uhta en russe) fin mars 1920 pour demander un référendum sur l'indépendance puis former une sorte de gouvernement provisoire. Mais Tchitcherine refuse le 25 mai 1920 toute idée de référendum, ce qui amène ledit gouvernement dissident à appeler à la " mobilisation générale " sous la houlette du capitaine Mata et de l'instituteur Parviainen. La rébellion reste toutefois circonscrite et les nationalistes caréliens fuient vers la Finlande fin juin ${ }^{152}$.

Malgré tout, les contacts ne sont pas coupés entre les deux camps. Le 29 avril 1920, Otto Wilhelm Kuusinen, l'un des hommes forts du Parti communiste

148 Ibid., p. 214.

149 Lénine, Euvres complètes, op. cit., t. XXX, p. 463.

150 Les discussions en interne commencent en février 1920 et portent essentiellement sur ces deux points : Mauno Jääskeläinen, Itä-Karjalan..., op. cit., p. 270-277.

151 Arvo Ylärakkola, Edvard Gylling..., op. cit., p. 167-168.

152 Mauno Jääskeläinen, Itä-Karjalan..., op. cit., p. 278. 
finlandais en exil et futur dirigeant du Komintern, envoie à Rafael Erich, son ancien condisciple et nouveau Premier ministre, un projet de paix entre les deux pays. Signé Otto Näre, l'un de ses pseudonymes d'auteur, son texte propose de donner Petsamo à la Finlande et d'organiser en Carélie un référendum pour ou contre le rattachement à la Finlande ; en contrepartie, les attaques des activistes doivent cesser le long de la frontière et les marchandises russes doivent pouvoir transiter vers l'Ouest par le territoire finlandais ${ }^{153}$. Rafael Erich étant resté muet, les dirigeants russes proposent le 11 mai de nouvelles discussions ${ }^{154}$. Le gouvernement d'Helsinki, pressé par le puissant groupe parlementaire social-démocrate, accepte de se remettre à la table des négociations ${ }^{155}$. Celles-ci s'ouvrent le 12 juin 1920 à Tartu, en Estonie.

Les discussions portant sur Petsamo et l'Ingrie sont relativement faciles. La partie finlandaise déclare ne pas avoir de vues particulières sur cette dernière province ; elle exige simplement que les droits culturels de la minorité de langue finnoise soient respectés par les Russes, ce que ceux-ci promettent de faire ${ }^{156}$. Les tractations sont plus difficiles sur la Carélie ${ }^{157}$. Les négociateurs envoyés par Helsinki se battent de nouveau pour les ressources forestières de Repola et Porajärvi. En outre, pris de court par l'annonce de la fondation récente (7 juin 1920) de la "Commune du peuple travailleur de Carélie ", ils ont, selon Youri Kilin, peur de voir tuer dans l'œuf le droit des Caréliens à l'indépendance ${ }^{158}$. Les débats traînent donc en longueur face à une délégation russe beaucoup plus tenace que deux ans plus tôt. La première étape vers un accord a néanmoins lieu le 13 août 1920 avec la signature d'un armistice entre les deux pays ${ }^{159}$. Une autre étape se dessine quand, le $1^{\text {er }}$ septembre 1920, le Comité d'aide aux Ingres est dissous et son président, J. P. Kokko, mis en accusation pour malversations ${ }^{160}$. Mais la lenteur de ces petits pas exaspère le bureau politique du PC(b)R qui enjoint le 2 octobre à ses propres négociateurs d'aboutir au plus vite à un accord ${ }^{161}$. Cette intervention semble avoir un bon effet puisque le 14 octobre 1920, les deux camps se décident à signer un traité de paix. La partie finlandaise sacrifie le rêve

153 Ce document figure in extenso dans John H. Hodgson, Edvard Gylling ja Otto W. Kuusinen..., op. cit., p. 136-153.

154 Cette proposition est dictée aussi par l'attaque polonaise foudroyante sur Kiev que les bolcheviks interprètent comme le signe d'une nouvelle intrigue des grandes puissances impérialistes.

155 Tuomo Polvinen et al., J.K. Paasikivi. Valtiomiehen elämäntyö (J. K. Paasikivi. La vie et l'auvre d'un homme d'État), t. II, 1918-1939, Helsinki - Porvoo, WSOY, 1992, p. 24-25.

156 Pekka Nevalainen, Rautaa Inkerin rajalla..., op. cit., p. 255.

157 Mauno Jääskeläinen, Itä-Karjalan..., op. cit., p. 278-315.

158 Juri Kilin, Suurvallan-rajamaa. Neuvosto-Karjala Neuvostovaltion politiikassa, 1920-1941 (Un pays frontalier d'une grande puissance. La Carélie soviétique dans la politique de l'État soviétique, 1920-1941), Jyväskylä, Studia Historica Septentrionalia 39, 2001, chap. II.

159 Arvo Ylärakkola, Edvard Gylling..., op. cit., p. 170.

160 Pekka Nevalainen, Rautaa Inkerin rajalla..., op. cit., p. 239-240.

161 Tuomo Polvinen, Venäjän vallankumous..., op. cit., t. II, p. 368-369. 
de la Grande Finlande à ses intérêts du moment et les Soviétiques acceptent de créer une commission mixte pour discuter de la reconnaissance de la Commune de Carélie ${ }^{162}$.

Les semaines qui suivent ne sont cependant pas de tout repos. En Finlande, les activistes n'acceptent pas les termes de l'accord, tandis qu'une partie importante de la droite ne le fait que du bout des lèvres. Au sein de la Coalition nationale (Kansallinen kokoomus), la principale formation conservatrice, Lauri Ingman a les pires difficultés à faire admettre aux autres dirigeants qu'il faut se résigner à la paix. Selon lui, Petrograd, la clé de la Carélie, ne peut pas être prise et il vaut mieux se montrer réaliste ${ }^{163}$. Les agrariens se montrent d'abord positifs puisque trois seulement de leurs députés refusent la ratification ; mais beaucoup, dont leur chef Santeri Alkio, considèrent qu'il faudra continuer la lutte en faveur de l'indépendance des Caréliens et des Ingres ${ }^{164}$. La ligne pragmatique finit par l'emporter et avec l'aide des sociaux-démocrates, le traité de Tartu est ratifié par le Parlement le $1^{\text {er }}$ décembre 1920. Kirjasalo est abandonné par les insurgés ingres quelques jours plus tard et l'Armée rouge réoccupe la zone qu'elle transforme en no man's land après avoir brûlé le village, preuve que la méfiance réciproque n’a pas disparu.

L'année 1921 confirme la persistance de graves difficultés. En avril, le congrès de la Coalition nationale voit une majorité de délégués critiquer vertement les partisans du traité de Tartu. Une motion exigeant l'autodétermination de la Carélie orientale est votée ${ }^{165}$. À la mi-octobre, l'Organisation des partisans caréliens (Karjalan metsäsissijärjestö), un groupe armé anticommuniste, dirigé par un trio composé de deux Caréliens et d'un activiste finlandais, décide de passer à l'action. Elle regroupe environ 3000 hommes, dont 500 venus de Finlande. Au cours des mois suivants, ceux-ci liquident la plupart des cadres communistes locaux et s'emparent de presque toute la Carélie blanche à l'exception des plus gros bourgs ${ }^{166}$. Mais le 20 janvier 1922, leur base arrière est détruite par un bataillon de skieurs d'élite emmené par Toivo Antikainen, un Finlandais " rouge " exilé en Russie et passé par l'École militaire internationale de Petrograd. Les insurgés sont obligés de refluer en désordre de l'autre côté de la frontière durant les semaines suivantes ${ }^{167}$. Officiellement, le gouvernement d'Helsinki ne soutient pas le soulèvement. Mais le gouvernement soviétique se montre très agacé de la situation ; Trotski serait même prêt à envisager une attaque punitive. Côté finlandais,

162 Arvo Ylärakkola, Edvard Gylling..., op. cit., p. 174 sq.

163 Porvarillisen työn arkisto (Archives de la Coalition nationale), réunion de la direction du parti, 24 octobre 1920.

164 Aulis J. Alanen, Santeri..., op. cit., p. 573.

165 Porvarillisen työn arkisto (Archives de la Coalition nationale), minutes du congrès, 10 avril 1920.

166 Mauno Jääskeläinen, Itä-Karjalan..., op. cit., p. 319-321 ; Jussi Niinistö, Heimosotien..., op. cit., chap. VII, p. 239-251.

167 Ibid., p. 252-260. 
certains songent sérieusement à une mobilisation générale et la guerre des communiqués bat son plein ${ }^{168}$; le président Ståhlberg impose cependant le calme. Finalement, à part quelques accrochages limités entre les troupes frontalières, le conflit ne dégénère pas sur le terrain ${ }^{169}$.

L'hiver 1922 est également agité sur le territoire finlandais. Le 2 février, éclate sur l'un des chantiers de la Kemi O.Y., près de Savukoski dans l'extrême nord du pays, une insurrection communiste appelée Révolte du lard (Läskikapina) ${ }^{170}$. Encadrés par des officiers rouges finlandais venus de Russie, près de 400 hommes, armés pour l'occasion, quittent leur lieu de travail et se dirigent vers Knäsö, sur la voie de chemin de fer de Mourmansk. Plus de 200 seront ensuite envoyés à l'École militaire internationale de Petrograd où 156 deviendront officiers de l'Armée rouge. Ce raid éclair, le seul de cette ampleur venu de Russie, se veut une réponse au soulèvement des partisans caréliens dont les dirigeants de la Commune de Carélie pensent qu'il est directement fomenté par les blancs finlandais ; Tchitcherine estime qu'une opération spectaculaire doit montrer au gouvernement de Helsinki, qui a saisi la SDN à propos de cette cette opération, que la ligne rouge ne doit pas être franchie ${ }^{171}$. Peu après, le 14 février 1922, un activiste assassine le ministre de l'Intérieur Heikki Ritavuori, au prétexte qu'il a empêché le libre passage de volontaires désireux de venir en aide aux insurgés caréliens, mais aussi parce que ce proche du président Ståhlberg est attaché au respect des droits des prisonniers de la guerre civile, contrairement à ses détracteurs d'extrême droite ${ }^{172}$.

Cet épisode, qui déclenche une vive émotion dans l'opinion publique, incite la direction finlandaise à accélérer les négociations avec les Soviétiques. Le $1^{\text {er }}$ juin 1922, est signé à Moscou un nouvel accord sur la frontière (Rajarauha) où les deux États s'engagent à respecter les limites définies par le traité de Tartu et à créer de part et d'autre une zone de sécurité où déplacements et droit de résidence sont fortement réglementés. Les contingents autorisés à surveiller cette zone sont fixés

168 UMA, Fl 12, 12 L, «Venäläiset pakolaiset Suomessa ja heidän avustamisensa 1922-1924 » ("Les réfugiés politiques russes et l'aide qui leur est accordée, 1922-1924») : rapport du chef de la police politique au ministre des Affaires étrangères qui a demandé de vérifier les assertions contenues dans une note de Tchitcherine du 16 janvier (dont ils cite certains passages) à propos de l'activité de groupes de Russes blancs et d'officiers finlandais dans la zone de Porajärvi et Repola (20 janvier 1922).

169 Ibid., p. 250 ; Juri Kilin, Suurvallan-rajamaa..., op. cit., p. 58-61.

170 Ce nom vient du fait que son dirigeant, Janne Myyryläinen (alias Jahvetti Moilanen), avait réussi à galvaniser les ouvriers présents en étant juché sur une caisse contenant du lard destiné au ravitaillement des bûcherons. Sur cet épisode, Markku Kangaspuro, Neuvosto-Karjalan taistelu..., op. cit., p. 112-125. À propos de Janne Myyryläinen, voir la biographie de Matti Lackman, Jahvetti Moilanen, läskikapinan johtaja. Poliittinen elämäkerta (1881-1938) (Jahvetti Moilanen, dirigeant de la Révolte du lard. Une biographie politique), Oulu, Oulun Historiaseuran, 1993.

171 Markku Kangaspuro, Neuvosto-Karjalan..., op. cit., p. 114-115.

172 Timo Silenti, Ritavuoren murha (L'assassinat de Ritavuori), mémoire de maîtrise, université d'Helsinki, 1995. 
de manière précise afin d'éviter tout incident. À partir de cette date et jusqu'à l'automne 1939, on peut considérer que la situation est globalement stabilisée car elle ne génère plus de conflits ouverts, ni de violations flagrantes du territoire d'autrui. Néanmoins, l'État finlandais, qui a fait appel à la SDN pour la résolution du problème carélien le 26 novembre 1921, réitère sa démarche le 18 avril 1923 en chargeant Rafael Erich de suivre cette affaire. Mais dans les deux cas, il n'obtient pas la réaction escomptée ${ }^{173}$.

\section{ConClusion}

Le premier enseignement à tirer est que la définition de la frontière russofinlandaise n'est pas une simple question bilatérale, car les enjeux de l'époque dépassent largement le cadre des rapports entre les deux pays. Il est donc vain de vouloir s'en tenir à une simple approche nationale et par certains côtés manichéenne. Le plus important n'est pas de savoir qui a voulu croquer l'autre, mais de comprendre que les deux États sont dépendants de facteurs sur lesquels ils n'ont qu'une capacité limitée d'intervention. Ainsi, l'évolution des rapports de force entre puissances belligérantes leur impose plus ou moins de retenue ou d'agressivité. Tant que le Reich est en mesure d'imposer sa loi à l'est, le gouvernement conservateur et monarchiste finlandais cherche à s'appuyer sur ce puissant allié, les bolcheviks n'ayant guère d'autres choix que de manœuvrer en recul en cherchant à obtenir des accords, fussent-ils défavorables. Quand la Royal Navy apparaît dans la Baltique avec la ferme intention de nuire aux menées révolutionnaires dans la région, il est tout aussi logique que les gouvernements anticommunistes cherchent à obtenir son appui, les dirigeants soviétiques étant une fois de plus, après l'échec de leur tentative de reconquête des pays baltes, contraints de chercher des solutions de compromis pour pouvoir consacrer leurs forces à repousser les assauts des Russes blancs.

Le deuxième enseignement, c'est que la question révolutionnaire, de nature tout à fait transnationale, est au cœur de tous les conflits régionaux, en particulier du différend russo-finlandais. Le désir d'écraser la Russie des conseils va de pair avec les haines accumulées en Finlande au cours de la terrible guerre civile de 1918. Il ne s'agit pas seulement de territoires à gagner ou à perdre, mais du type de société que les uns et les autres souhaitent. Il est tout de même caractéristique d'observer que les gouvernements conservateurs finlandais répugnent moins à envisager une coordination avec les Russes blancs, les pires ennemis de leur indépendance, qu'avec les bolcheviks qui l'ont soutenue en 1917 et réaffirmée par la suite. Il est intéressant également de voir que la Délégation du peuple, loin de renoncer à l'idée d'annexer la Carélie, a même proposé cette option aux négociateurs russes, sans rencontrer d'opposition systématique de leurs interlocuteurs.

173 Mauno Jääskeläinen, Itä-Karjalan..., op. cit., p. 322-323. 
En clair, l'opposition entre blancs et rouges est manifestement plus forte que celle entre Russes et Finlandais, décrétée éternelle par leurs nationalistes. Se focaliser sur les seuls intérêts nationaux dans une période aussi marquée par les conflits sociopolitiques est une erreur de perspective, donc de méthode, bien qu'il faille bien sûr les prendre aussi en compte.

Le troisième enseignement, corollaire du précédent, c'est qu'il n'y a pas d'homogénéité absolue au sein des gouvernements et des partis quant aux solutions à trouver. Seuls les nationalistes fanatiques présentent un front homogène de part et d'autre. De plus, les positions individuelles ou collectives évoluent en fonction des situations. Cela rend parfois difficile la lecture des événements, mais montre aussi qu'en politique le pragmatisme l'emporte souvent sur l'idéologie.

Enfin, dernier enseignement, la direction soviétique, sauf à de courtes périodes, a fait preuve à cette époque-là d'une volonté de négociation plus affirmée en général que celle des responsables finlandais, même en considérant que ces derniers n'ont pas une approche homogène des questions internationales. Au final d'ailleurs, les Finlandais ont gagné Petsamo et ont vu confirmée leur présence dans l'Isthme de Carélie et sur les rives du Ladoga, ce qui n'avait rien de si évident au regard du passé. Ce fait ne peut pas simplement être mis au compte de la faiblesse conjoncturelle des bolcheviks ; il a aussi à voir avec une stratégie plus ancienne, reconnaissant à la Finlande le droit à l'autodétermination, ce que même un activiste comme Gummerus est amené à constater ${ }^{174}$. Certes l'extension de la révolution à la Finlande et à la Scandinavie n'est pas une idée étrangère aux commissaires du peuple, mais elle n'implique pas automatiquement dans leur esprit la disparition de toute frontière et de toute indépendance. En outre, elle n'est pas à ce point formalisée qu'on puisse parler d'un projet établi. 